\title{
Adsorption Isotherms and Kinetics of Multi-Walled Carbon Nano- tubes (MWCNTs), Boron Nitride Nanotubes (BNNTs), Amorphous Boron Nitride Nanotubes (a-BNNTs) and Hexagonal Boron Nitride Nanotubes (h-BNNTs) for Eliminating Carcinoma, Sarcoma, Lym- phoma, Leukemia, Germ Cell Tumor and Blastoma Cancer Cells and Tissues
}

\author{
Alireza Heidari* \\ Faculty of Chemistry, California South University, USA
}

*Corresponding author: Alireza Heidari, Faculty of Chemistry, California South University, 14731 Comet St. Irvine, CA 92604, USA, E-mail:Scholar.Researcher.Scientist@gmail.com; Alireza.Heidari@calsu.us

\begin{abstract}
Hydron, Transhumanism, H (S-train), Humanity ${ }^{+}$(Humanity Plus), electron hole and Evolved High Speed Packet Access (or $\mathrm{HSPA}^{+}$or HSPA (Plus) or HSPAP) from environment into human blood causes human blood cancer cells and tissues. Diagnosis and treatment of such human blood cancer before it is discharged into the human blood is essential. The present study investigated Hydron, Transhumanism, H (S-train), Humanity ${ }^{+}$(Humanity Plus), electron hole and Evolved High Speed Packet Access (or HSPA ${ }^{+}$or HSPA (Plus) or HSPAP) adsorption from human blood cancer cells and tissues using Multi-Walled Carbon Nanotubes (MWCNTs), Boron Nitride Nanotubes (BNNTs), Amorphous Boron Nitride Nanotubes (a-BNNTs) and Hexagonal Boron Nitride Nanotubes (h-BNNTs) as the adsorbent for eliminating carcinoma, sarcoma, lymphoma, leukemia, germ cell tumor and blastoma cancer cells and tissues from human blood. This was an experimental study at laboratory scale in a batch system. The adsorbent was characterized using X-Ray Diffraction (XRD), Transmission Electron Microscopy (TEM), Atomic Force Microscopy (AFM), Scanning Electron Microscopy (SEM), Attenuated Total Reflectance Fourier Transform Infrared (ATR-FTIR) spectroscopy, Raman spectroscopy, Differential Thermal Analysis-Thermal Gravim Analysis (DTA-TGA) and Energy-Dispersive X-Ray Spectroscopy (EDX). The variables affecting Hydron, Transhumanism, H (S-train), Humanity ${ }^{+}$(Humanity Plus), electron hole and Evolved High Speed Packet Access (or $\mathrm{HSPA}^{+}$or HSPA (Plus) or HSPAP) adsorption were amount of adsorbent, initial concentration of Hydron,
\end{abstract}

Hydron, Transhumanism, $\mathrm{H}$ (S-train), Humanity ${ }^{+}$(Humanity Plus), electron hole and Evolved High Speed Packet Access (or $\mathrm{HSPA}^{+}$or HSPA (Plus) or HSPAP) from environment into human blood causes human blood cancer cells and tissues. Diagnosis and treatment of such human blood cancer before it is discharged into the human blood is essential. The present study investigated Hydron, Transhumanism, H (S-train), Humanity ${ }^{+}$(Humanity Plus), electron hole and Evolved High Speed Packet Access (or HSPA ${ }^{+}$or HSPA (Plus) or HSPAP) adsorption from human blood cancer cells and tissues using Multi-Walled Carbon Nanotubes (MWCNTs), Boron Nitride Nanotubes (BNNTs), Amorphous Boron Nitride Nanotubes (a-BNNTs) and Hexagonal Boron Nitride Nanotubes (h-BNNTs) as the adsorbent for eliminating carcinoma, sarcoma, lymphoma, leukemia, germ cell tumor and blastoma cancer cells and tissues from human blood. This was an experimental study at laboratory scale in a batch system. The adsorbent was characterized using X-Ray Diffraction (XRD), Transmission Electron Microscopy (TEM), Atomic Force Microscopy (AFM), Scanning Electron Microscopy (SEM), Attenuated Total Reflectance Fourier Transform Infrared (ATR-FTIR) spectroscopy, Raman spectroscopy, Differential Thermal Analysis-Thermal Gravim Analysis (DTA-TGA) and Energy-Dispersive X-Ray Spectroscopy (EDX). The variables affecting Hydron, Transhumanism, H (S-train), Humanity ${ }^{+}$(Humanity Plus), electron hole and Evolved High Speed Packet Access (or $\mathrm{HSPA}^{+}$or HSPA (Plus) or HSPAP) adsorption were amount of adsorbent, initial concentration of Hydron, Transhumanism, $\mathrm{H}$ (S-train), Humanity ${ }^{+}$(Humanity Plus), electron hole

Citation: Heidari A (2018) Adsorption Isotherms and Kinetics of Multi-Walled Carbon Nanotubes (MWCNTs), Boron Nitride Nanotubes (BNNTs), Amorphous Boron Nitride Nanotubes (a-BNNTs) and Hexagonal Boron Nitride Nanotubes (h-BNNTs) for Eliminating Carcinoma, Sarcoma, Lymphoma, Leukemia, Germ Cell Tumor and Blastoma Cancer Cells and Tissues. Clin Med Rev Case Rep 5:201. doi. org/10.23937/2378-3656/1410201

Accepted: January 29, 2018: Published: January 31, 2018

Copyright: (c) 2018 Heidari A. This is an open-access article distributed under the terms of the Creative Commons Attribution License, which permits unrestricted use, distribution, and reproduction in any medium, provided the original author and source are credited. 
and Evolved High Speed Packet Access (or $\mathrm{HSPA}^{+}$or HSPA (Plus) or HSPAP) and $\mathrm{pH}$. Isotherm and kinetic models were employed to evaluate the data. The results indicate that the elevation of $\mathrm{pH}$ and the amount of adsorbent increased the efficiency of Hydron, Transhumanism, $\mathrm{H}$ (S-train), Humanity ${ }^{+}$(Humanity Plus), electron hole and Evolved High Speed Packet Access (or $\mathrm{HSPA}^{+}$or HSPA (Plus) or HSPAP) adsorption, while an increase in Hydron, Transhumanism, H (S-train), Humanity ${ }^{+}$(Humanity Plus), electron hole and Evolved High Speed Packet Access (or $\mathrm{HSPA}^{+}$or HSPA (Plus) or HSPAP) concentration decreased adsorption. The results also show that Hydron, Transhumanism, H (S-train), Humanity ${ }^{+}$(Humanity Plus), electron hole and Evolved High Speed Packet Access (or HSPA ${ }^{+}$ or HSPA (Plus) or HSPAP) adsorption follows a Langmuir isotherm model with a maximum adsorption capacity for Hydron, Transhumanism, H (S-train), Humanity ${ }^{+}$(Humanity Plus), electron hole and Evolved High Speed Packet Access (or $\mathrm{HSPA}^{+}$or HSPA (Plus) or HSPAP). Pseudo-first-order, pseudo-second-order and intraparticle kinetics were used to determine the adsorption kinetics. The experimental results showed a good correlation with the pseudo-second-order kinetic model. The results revealed that Multi-Walled Carbon Nanotubes (MWCNTs), Boron Nitride Nanotubes (BNNTs), Amorphous Boron Nitride Nanotubes (a-BNNTs) and Hexagonal Boron Nitride Nanotubes (h-BNNTs) for eliminating carcinoma, sarcoma, lymphoma, leukemia, germ cell tumor and blastoma cancer cells and tissues from human blood are a high-capacity adsorbent which can be used for removal of contaminants.

\section{Keywords}

Multi-Walled Carbon Nanotubes (MWCNTs), Boron Nitride Nanotubes (BNNTs), Amorphous Boron Nitride Nanotubes (a-BNNTs), Hexagonal Boron Nitride Nanotubes (h-BNNTs), Cancer cells and tissues, Human blood

\section{Introduction}

Hydron, Transhumanism, H (S-train), Humanity (Humanity Plus), electron hole and Evolved High Speed Packet Access (or HSPA ${ }^{+}$or HSPA (Plus) or HSPAP) are major toxic compounds found in environment. The mean level of Hydron, Transhumanism, $\mathrm{H}$ (S-train), Humanity ${ }^{+}$(Humanity Plus), electron hole and Evolved High Speed Packet Access (or HSPA ${ }^{+}$or HSPA (Plus) or HSPAP) in human blood is 1 (ppb) [1-10], depending on the site of discharge. The presence of Hydron, Transhumanism, $\mathrm{H}$ (S-train), Humanity ${ }^{+}$(Humanity Plus), electron hole and Evolved High Speed Packet Access (or HSPA or HSPA (Plus) or HSPAP) in the environment, especially water resources, can lead to human blood cancer cells and tissues [11-22]. The acceptable value for Hydron, Transhumanism, H (S-train), Humanity ${ }^{+}$(Humanity Plus), electron hole and Evolved High Speed Packet Access (or $\mathrm{HSPA}^{+}$or HSPA (Plus) or HSPAP) discharged into human blood cancer cells and tissues of diagnosis and treatment is 0.05 to $0.2 \mathrm{mg} / \mathrm{L}$, depending on the plan site and the potential effect on the human blood cell and tissues [23-39].

Hydron, Transhumanism, H (S-train), Humanity ${ }^{+}$(Humanity Plus), electron hole and Evolved High Speed Packet Access (or $\mathrm{HSPA}^{+}$or HSPA (Plus) or HSPAP) in human blood cell and tissues, with $1 \%$ to $4 \%$ of human blood cell and tissues Hydron, Transhumanism, H (S-train), Humanity ${ }^{+}$(Humanity Plus), electron hole and Evolved High Speed Packet Access (or HSPA ${ }^{+}$or HSPA (Plus) or HSPAP) occurring in the form of Hydron, Transhumanism, $\mathrm{H}$ (S-train), Humanity ${ }^{+}$(Humanity Plus), electron hole and Evolved High Speed Packet Access (or HSPA ${ }^{+}$or HSPA (Plus) or HSPAP). Because Hydron, Transhumanism, $\mathrm{H}$ (S-train), Humanity ${ }^{+}$(Humanity Plus), electron hole and Evolved High Speed Packet Access (or HSPA ${ }^{+}$or HSPA (Plus) or HSPAP) are essential nutrients for the growth of photosynthetic algae and cyanobacteria, their presence can cause cancer in human blood cells and tissues. The growth of cancer is accelerated in the human blood cells and tissues after being enriched with these nutrients (Hydron, Transhumanism, H (S-train), Humanity ${ }^{+}$ (Humanity Plus), electron hole and Evolved High Speed Packet Access (or HSPA' or HSPA (Plus) or HSPAP)). This phenomenon consumes dissolved Oxygen in the human blood cancer cells and tissues and disrupts life in these environments by Oxygen deficits [40-64].

Hydron, Transhumanism, H (S-train), Humanity ${ }^{+}(\mathrm{Hu}-$ manity Plus), electron hole and Evolved High Speed Packet Access (or $\mathrm{HSPA}^{+}$or HSPA (Plus) or HSPAP) are major factors for controlling human blood cancer. It is essential that the Hydron, Transhumanism, $\mathrm{H}$ (S-train), Humanity ${ }^{+}$ (Humanity Plus), electron hole and Evolved High Speed Packet Access (or HSPA ${ }^{+}$or HSPA (Plus) or HSPAP) present in human blood cancer cells and tissues is adsorbed using suitable methods and brought to acceptable levels [65-73]. Adsorption of Hydron, Transhumanism, $\mathrm{H}$ (S-train), Humanity ${ }^{+}$(Humanity Plus), electron hole and Evolved High Speed Packet Access (or HSPA ${ }^{+}$or HSPA (Plus) or HSPAP) from human cancer cells and tissues occurs at advanced stages of human blood cancer treatment. The most common methods used for removal of Hydron, Transhumanism, H (S-train), Humanity ${ }^{+}$(Humanity Plus), electron hole and Evolved High Speed Packet Access (or $\mathrm{HSPA}^{+}$or HSPA (Plus) or HSPAP) are biological and chemical precipitation. Biological methods are less commonly used because of their long retention times and operational problems [74-84].

In chemical methods, precipitators such as Cadmium Oxide (CdO) nanoparticles as well as Nano compounds such as Ruthenium (IV) Oxide $\left(\mathrm{RuO}_{2}\right)$, Rhodium (III) Oxide $\left(\mathrm{Rh}_{2} \mathrm{O}_{3}\right)$, Iridium (IV) Oxide (IrO $\left.{ }_{2}\right)$, Rhenium (IV) Oxide $\left(\mathrm{ReO}_{2}\right)$ and Rhenium (VII) Oxide $\left(\mathrm{O}_{7} \mathrm{Re}_{2}\right)$ make it possible to precipitate Hydron, Transhumanism, H (S-train), Humanity ${ }^{+}$(Humanity Plus), electron hole and Evolved High Speed Packet Access (or HSPA ${ }^{+}$or HSPA (Plus) or HSPAP) within a relatively acidic $\mathrm{pH}$ range and then remove it from the human blood cancer cells and tissues [85-91]. This method is faster when removal of the contaminant of interest occurs at a shorter duration; however, there are major limitations in this method. These include sensitivity of adjustment of coagulator concentration, the need for constant monitoring, elevation of Iron concentration, changes in blood color, high amounts of sludge 
produced, high operational costs, decreased sedimentation, sludge DE blooding, changes in $\mathrm{pH}$ and the need to neutralize treated human blood cancer cells and tissues [92-109].

Electro-coagulation has attracted a great deal of attention in recent years, but study of its efficiency for removal of Hydron, Transhumanism, H (S-train), Humanity ${ }^{+}$(Humanity Plus), electron hole and Evolved High Speed Packet Access (or HSPA ${ }^{+}$or HSPA (Plus) or HSPAP) from human blood cancer cells and tissues has been limited. The application of Nano-filters has demonstrated their high efficiency (about 95\% removal of input Hydron, Transhumanism, H (S-train), Humanity ${ }^{+}$(Humanity Plus), electron hole and Evolved High Speed Packet Access (or HSPA ${ }^{+}$or HSPA (Plus) or HSPAP)) on an experimental scale. Heidari, et al. first removed organic compounds and nutrients using nanofiltration [21]. Despite the $95 \%$ efficiency for removal of Hydron, Transhumanism, $\mathrm{H}$ (S-train), Humanity ${ }^{+}$(Humanity Plus), electron hole and Evolved High Speed Packet Access (or HSPA ${ }^{+}$ or HSPA (Plus) or HSPAP) from human blood cells and tissues, this project did not become operational because it was expensive and uneconomical [110-128]. Heidari, et al. used Cadmium Oxide (CdO) powder to remove Hydron, Transhumanism, $\mathrm{H}$ (S-train), Humanity ${ }^{+}$ (Humanity Plus), electron hole and Evolved High Speed Packet Access (or HSPA ${ }^{+}$or HSPA (Plus) or HSPAP) from human blood cancer cells and tissues and ushered in the application of adsorbents for removal of Hydron, Transhumanism, $\mathrm{H}$ (S-train), Humanity ${ }^{+}$(Humanity Plus), electron hole and Evolved High Speed Packet Access (or HSPA ${ }^{+}$or HSPA (Plus) or HSPAP) [21].

Heidari, et al. removed Hydron, Transhumanism, $\mathrm{H}$ (S-train), Humanity ${ }^{+}$(Humanity Plus), electron hole and Evolved High Speed Packet Access (or HSPA ${ }^{+}$or HSPA (Plus) or HSPAP) using human blood cancer cells and tissues sludge adsorbent and Galarneau and Gehr employed walnut skins for removal of Hydron, Transhumanism, $\mathrm{H}$ (S-train), Humanity ${ }^{+}$(Humanity Plus), electron hole and Evolved High Speed Packet Access (or HSPA ${ }^{+}$ or HSPA (Plus) or HSPAP) from human blood cancer cells and tissues [21-153]. Many researchers have dealt with removal of Hydron, Transhumanism, $\mathrm{H}$ (S-train), Humanity $^{+}$(Humanity Plus), electron hole and Evolved High Speed Packet Access (or HSPA ${ }^{+}$or HSPA (Plus) or HSPAP) using various adsorbents. The adsorbents used for removing Hydron, Transhumanism, $\mathrm{H}$ (S-train), Humanity ${ }^{+}$ (Humanity Plus), electron hole and Evolved High Speed Packet Access (or HSPA ${ }^{+}$or HSPA (Plus) or HSPAP) from human blood cancer cells and tissues are divided into natural and artificial groups [129-139]. Goethite ( $\alpha$-FeO $(\mathrm{OH})$ ), volatile ash and eggshells are Nano-compounds used as adsorbents of Hydron, Transhumanism, $\mathrm{H}$ (S-train), Humanity ${ }^{+}$(Humanity Plus), electron hole and Evolved High Speed Packet Access (or $\mathrm{HSPA}^{+}$or HSPA (Plus) or HSPAP) from contaminated human blood cancer cells and tissues. If the proper adsorbent is chosen, adsorption can lower the level of Hydron, Transhumanism, $\mathrm{H}$ (S-train), Humanity ${ }^{+}$(Humanity Plus), electron hole and Evolved High Speed Packet Access (or HSPA or HSPA (Plus) or HSPAP) in human blood cancer cells and tissues to less than $0.0001 \mathrm{mg} / \mathrm{L}$. During adsorption, a gas or liquid component is transferred onto the surface of a solid. There are increasing applications in industry for removal of toxic compounds from the human blood cancer cells and tissues by adsorption [140-163].

Multi-Walled Carbon Nanotubes (MWCNTs), Boron Nitride Nanotubes (BNNTs), Amorphous Boron Nitride Nanotubes (a-BNNTs) and Hexagonal Boron Nitride Nanotubes (h-BNNTs) for eliminating carcinoma, sarcoma, lymphoma, leukemia, germ cell tumor and blastoma cancer cells and tissues from human blood are a new form of nanotubes with unique characteristics such as small size, high area specific surface, a hollow tube-like structure, high mechanical strength, and considerable electrical conductivity [164-173]. Nanotubes are classified as single-walled (SWNTs) and multi-walled (MWNTs). They can show a behavior similar to that of metals or semi-conductors depending on their diameter and characteristics. These behaviors usually originate from the development and arrangement of their Nanolayers [164-173].

Multi-Walled Carbon Nanotubes (MWCNTs), Boron Nitride Nanotubes (BNNTs), Amorphous Boron Nitride Nanotubes (a-BNNTs) and Hexagonal Boron $\mathrm{Ni}$ tride Nanotubes (h-BNNTs) for eliminating carcinoma, sarcoma, lymphoma, leukemia, germ cell tumor and blastoma cancer cells and tissues from human blood have been extensively investigated as adsorbents for the preconcentration and treatment of environmental contaminants, including organic and inorganic and radio-nucleotide compounds in large volumes of human blood cancer cells and tissues [150-169]. Studies have evaluated the application of these nanomaterials for the removal of contaminants such as micropollutants, heavy metals, radio-nucleotides, chemical organic compounds and hazardous compounds from gas currents [100-173]. Multi-Walled Carbon Nanotubes (MWCNTs), Boron Nitride Nanotubes (BNNTs), Amorphous Boron Nitride Nanotubes (a-BNNTs) and Hexagonal Boron Nitride Nanotubes (h-BNNTs) can also be used in the fabrication of transistors, field emission screens, Nano-lithography and biosensors [158-173].

The present study examined the efficiency of MultiWalled Carbon Nanotubes (MWCNTs), Boron Nitride Nanotubes (BNNTs), Amorphous Boron Nitride Nanotubes (a-BNNTs) and Hexagonal Boron Nitride Nanotubes (h-BNNTs) for eliminating carcinoma, sarcoma, lymphoma, leukemia, germ cell tumor and blastoma cancer cells and tissues from human blood in adsorption of Hydron, Transhumanism, H (S-train), Humanity ${ }^{+}$(Humanity Plus), electron hole and Evolved High Speed Packet Access (or $\mathrm{HSPA}^{+}$or HSPA (Plus) or HSPAP) from aqueous solu- 
tions. The factors studied were $\mathrm{pH}$, adsorbent concentration, Hydron, Transhumanism, $\mathrm{H}$ (S-train), Humanity ${ }^{+}$ (Humanity Plus), electron hole and Evolved High Speed Packet Access (or $\mathrm{HSPA}^{+}$or HSPA (Plus) or HSPAP) concentration and contact time. The adsorption kinetics and isotherms were also investigated.

\section{Materials, Research Method and Experimental Techniques}

Cadmium Oxide (CdO) nanoparticles were purchased from the Merck Company (Germany). Multi-Walled Carbon Nanotubes (MWCNTs), Boron Nitride Nanotubes (BNNTs), Amorphous Boron Nitride Nanotubes (a-BNNTs) and Hexagonal Boron Nitride Nanotubes (h-BNNTs) were obtained from the American International Standards Institute (AISI) (USA). Other chemicals used in the study were supplied by the Merck Company (Germany), too.

X-Ray Diffraction (XRD) analysis, Transmission Electron Microscopy (TEM), Atomic Force Microscopy

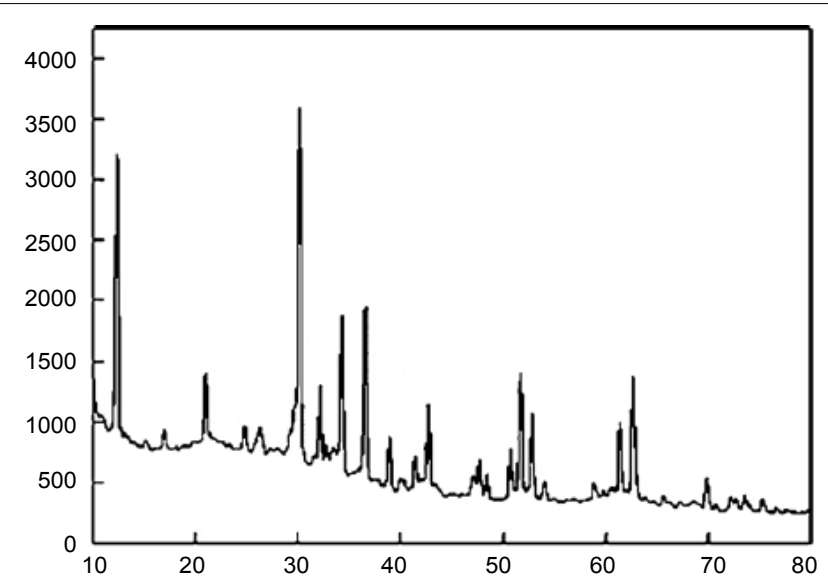

Figure 1: X-Ray Diffraction (XRD) analysis of MultiWalled Carbon Nanotubes (MWCNTs) as the adsorbent for eliminating carcinoma, sarcoma, lymphoma, leukemia, germ cell tumor and blastoma cancer cells and tissues in human blood. It should be noted that $y$-axis shows intensity and also $x$-axis shows diffraction angle $2 \theta$ (degree).

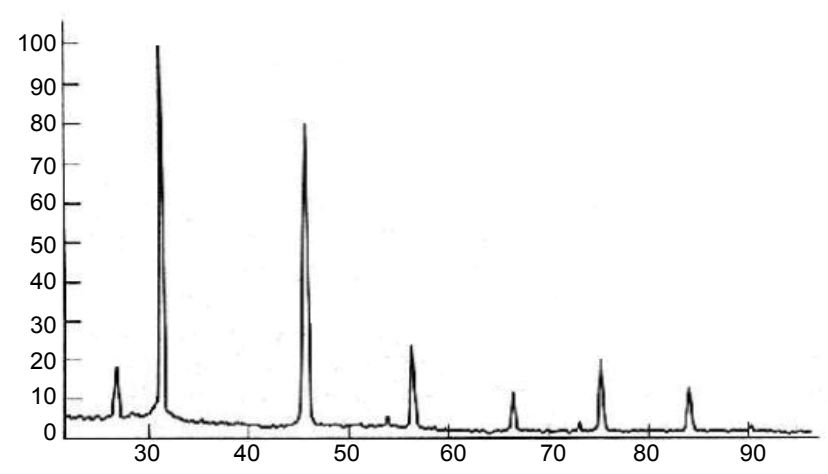

Figure 2: X-Ray Diffraction (XRD) analysis of Boron Nitride Nanotubes (BNNTs) as the adsorbent for eliminating carcinoma, sarcoma, lymphoma, leukemia, germ cell tumor and blastoma cancer cells and tissues in human blood. It should be noted that $y$-axis shows intensity and also $x$-axis shows diffraction angle $2 \theta$ (degree).
(AFM), Scanning Electron Microscopy (SEM), Attenuated Total Reflectance Fourier Transform Infrared (ATR-FTIR) spectroscopy, Raman spectroscopy, Differential Thermal Analysis-Thermal Gravim Analysis (DTA-TGA) and Energy-Dispersive X-Ray Spectroscopy (EDX) images of the Multi-Walled Carbon Nanotubes (MWCNTs), Boron Nitride Nanotubes (BNNTs), Amorphous Boron Nitride Nanotubes (a-BNNTs) and Hexagonal Boron Nitride Nanotubes (h-BNNTs) are shown in Figure 1, Figure 2, Figure 3, Figure 4, Figure 5, Figure 6, Figure 7, Figure 8, Figure 9, Figure 10, Figure 11, Figure 12, Figure 13, Figure 14, Figure 15, Figure 16, Figure 17, Figure 18, Figure 19, Figure 20, Figure 21, Figure 22, Figure 23, Figure 24, Figure 25, Figure 26, Figure 27, Figure 28, Figure 29, Figure 30, Figure 31 and Figure 32 respectively. The external diameter of the Multi-Walled Carbon Nanotubes (MWCNTs), Boron Nitride Nanotubes (BNNTs), Amorphous Boron Nitride Nanotubes (a-BNNTs) and Hexag-

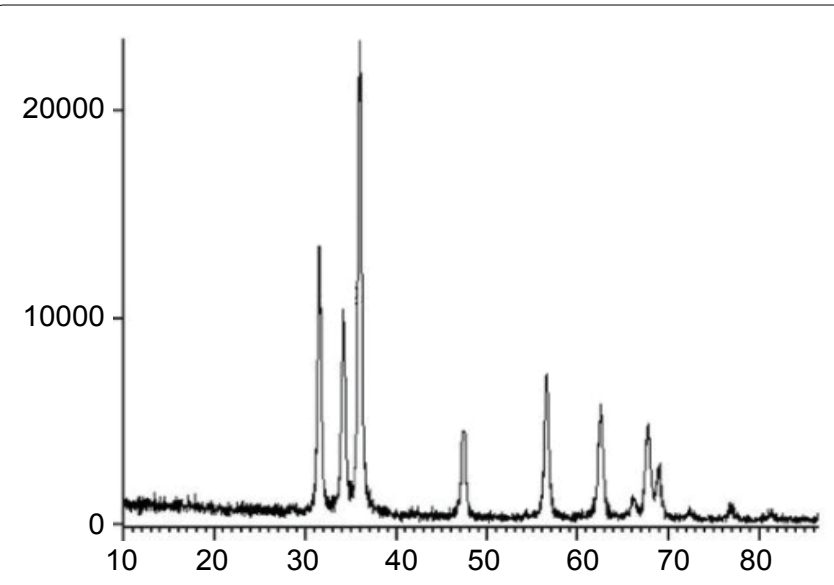

Figure 3: X-Ray Diffraction (XRD) analysis of Amorphous Boron Nitride Nanotubes (a-BNNTs) as the adsorbent for eliminating carcinoma, sarcoma, lymphoma, leukemia, germ cell tumor and blastoma cancer cells and tissues in human blood. It should be noted that $y$-axis shows intensity and also $x$-axis shows diffraction angle $2 \theta$ (degree).

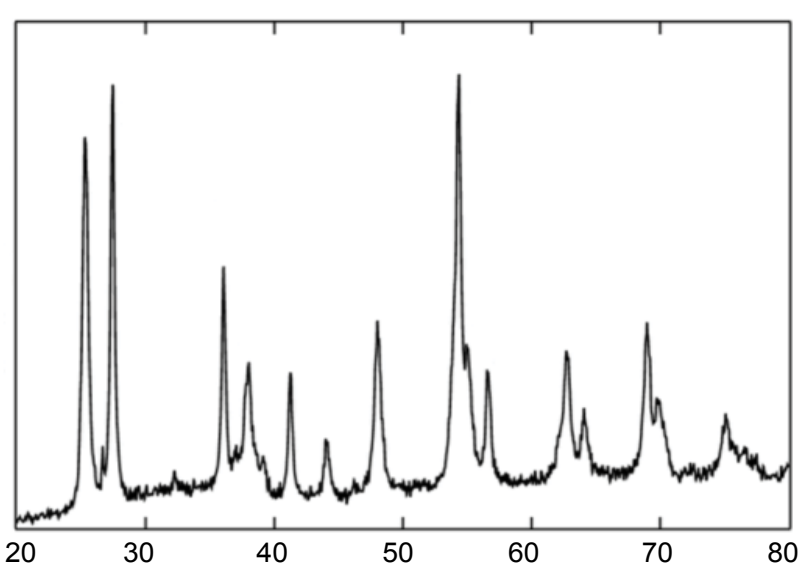

Figure 4: X-Ray Diffraction (XRD) analysis of Hexagonal Boron Nitride Nanotubes (h-BNNTs) as the adsorbent for eliminating carcinoma, sarcoma, lymphoma, leukemia, germ cell tumor and blastoma cancer cells and tissues in human blood. It should be noted that $y$-axis shows intensity and also $x$-axis shows diffraction angle $2 \theta$ (degree). 


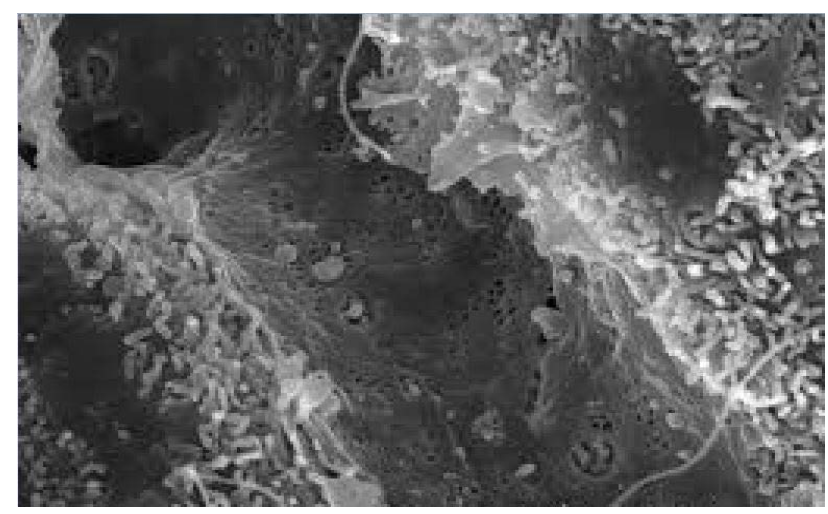

Figure 5: Transmission Electron Microscopy (TEM) image (scale $50(\mathrm{~nm})$ ) of Multi-Walled Carbon Nanotubes (MWCNTs) as the adsorbent for eliminating carcinoma, sarcoma, lymphoma, leukemia, germ cell tumor and blastoma cancer cells and tissues in human blood.

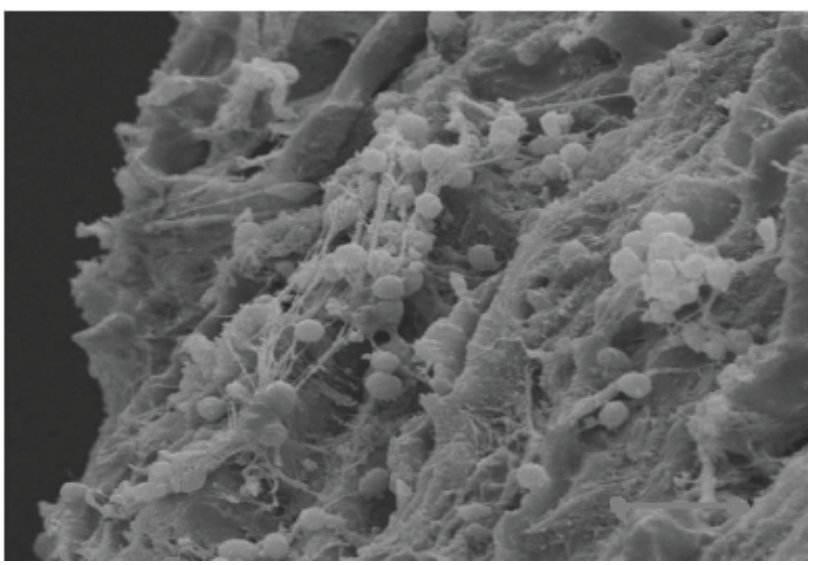

Figure 6: Transmission Electron Microscopy (TEM) image (scale $50(\mathrm{~nm})$ ) of Boron Nitride Nanotubes (BNNTs) as the adsorbent for eliminating carcinoma, sarcoma, lymphoma, leukemia, germ cell tumor and blastoma cancer cells and tissues in human blood.

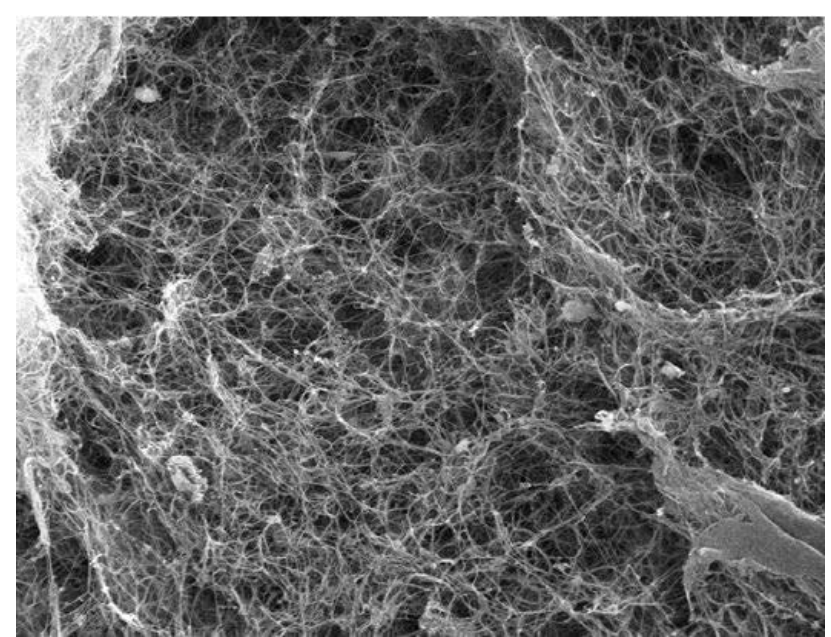

Figure 7: Transmission Electron Microscopy (TEM) image (scale $50(\mathrm{~nm})$ ) of Amorphous Boron Nitride Nanotubes (a-BNNTs) as the adsorbent for eliminating carcinoma, sarcoma, lymphoma, leukemia, germ cell tumor and blastoma cancer cells and tissues in human blood.

onal Boron Nitride Nanotubes (h-BNNTs) was between 5-50 (nm) and internal diameter was $7.9(\mathrm{~nm})$. The

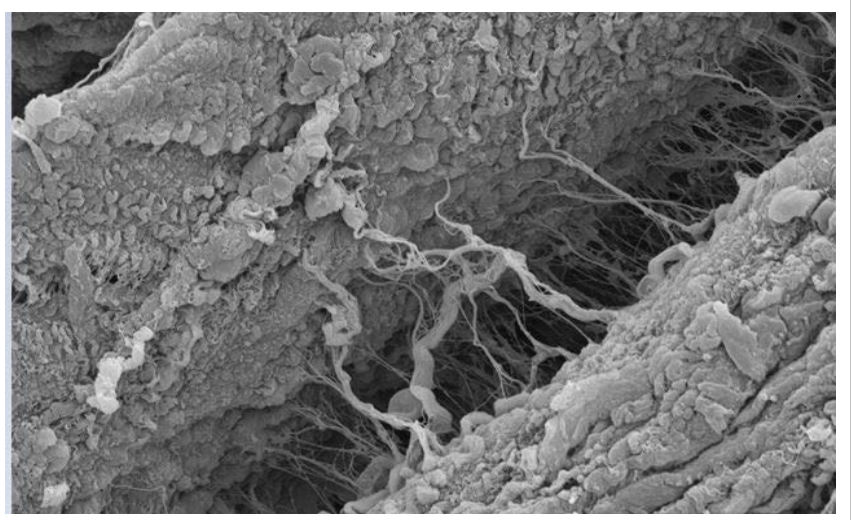

Figure 8: Transmission Electron Microscopy (TEM) image (scale $50(\mathrm{~nm})$ ) of Hexagonal Boron Nitride Nanotubes (h-BNNTs) as the adsorbent for eliminating carcinoma, sarcoma, lymphoma, leukemia, germ cell tumor and blastoma cancer cells and tissues in human blood.

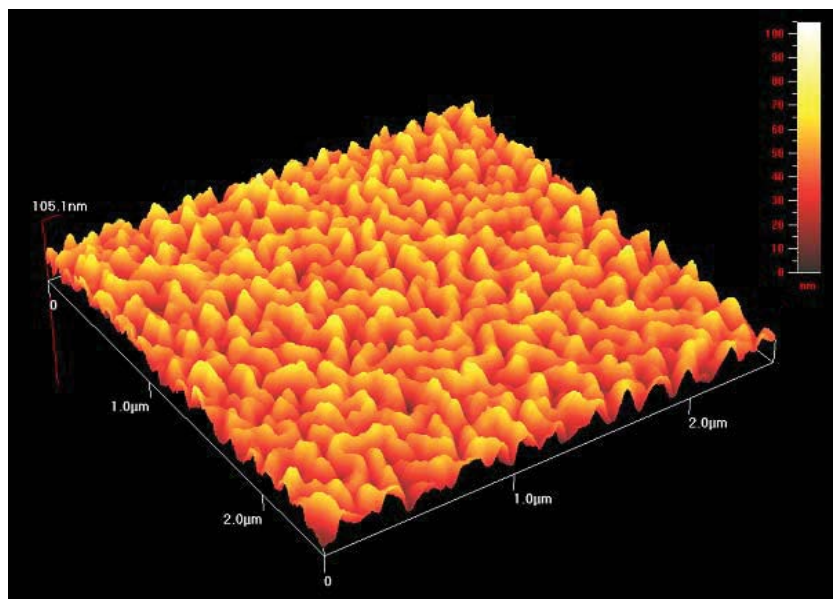

Figure 9: Atomic Force Microscopy (AFM) image of MultiWalled Carbon Nanotubes (MWCNTs) as the adsorbent for eliminating carcinoma, sarcoma, lymphoma, leukemia, germ cell tumor and blastoma cancer cells and tissues in human blood.

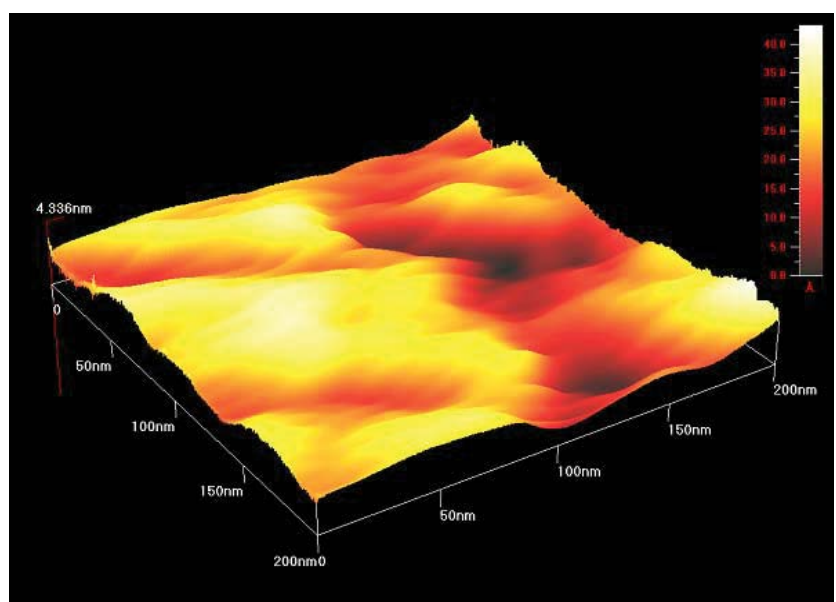

Figure 10: Atomic Force Microscopy (AFM) image of Boron Nitride Nanotubes (BNNTs) as the adsorbent for eliminating carcinoma, sarcoma, lymphoma, leukemia, germ cell tumor and blastoma cancer cells and tissues in human blood.

length was $6(\mu \mathrm{m})$ with a specific area of $230 \mathrm{~m}^{2} / \mathrm{g}$ and a purity of $98 \%$. 


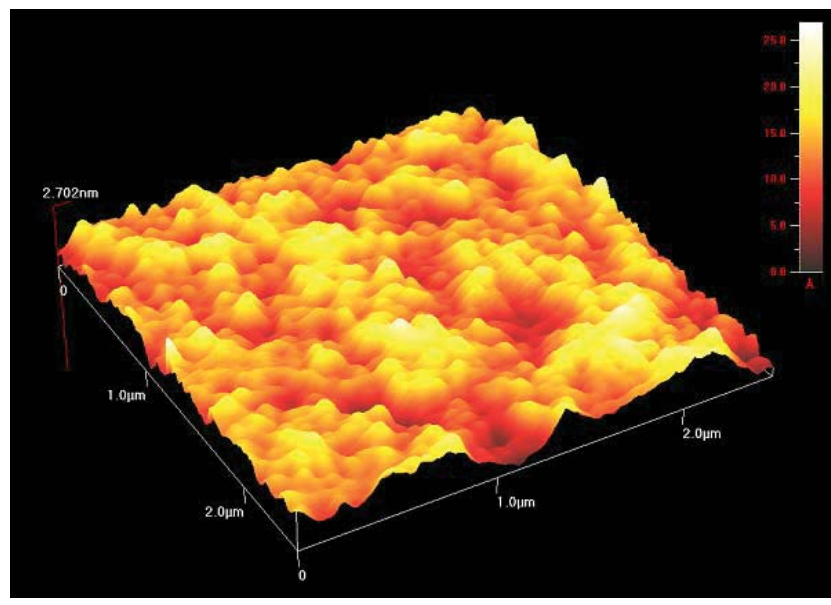

Figure 11: Atomic Force Microscopy (AFM) image of Amorphous Boron Nitride Nanotubes (a-BNNTs) as the adsorbent for eliminating carcinoma, sarcoma, lymphoma, leukemia, germ cell tumor and blastoma cancer cells and tissues in human blood.

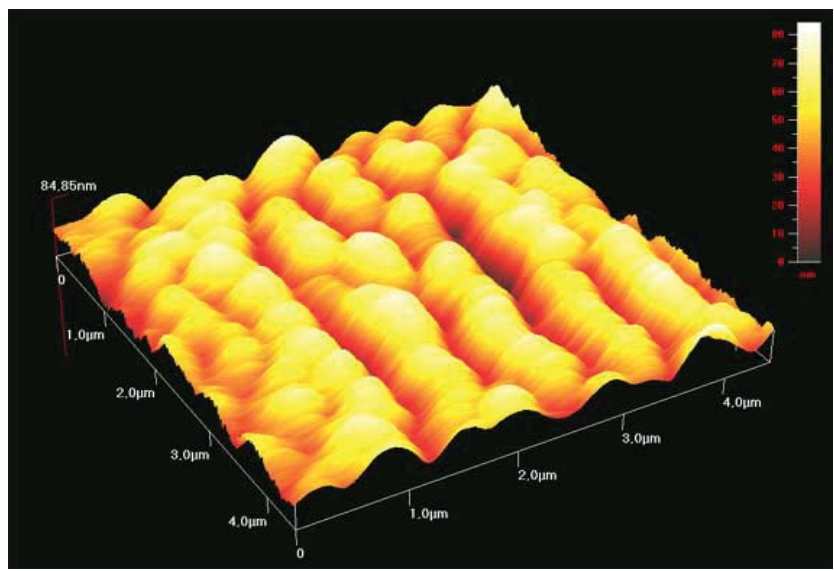

Figure 12: Atomic Force Microscopy (AFM) image of Hexagonal Boron Nitride Nanotubes (h-BNNTs) as the adsorbent for eliminating carcinoma, sarcoma, lymphoma, leukemia, germ cell tumor and blastoma cancer cells and tissues in human blood.

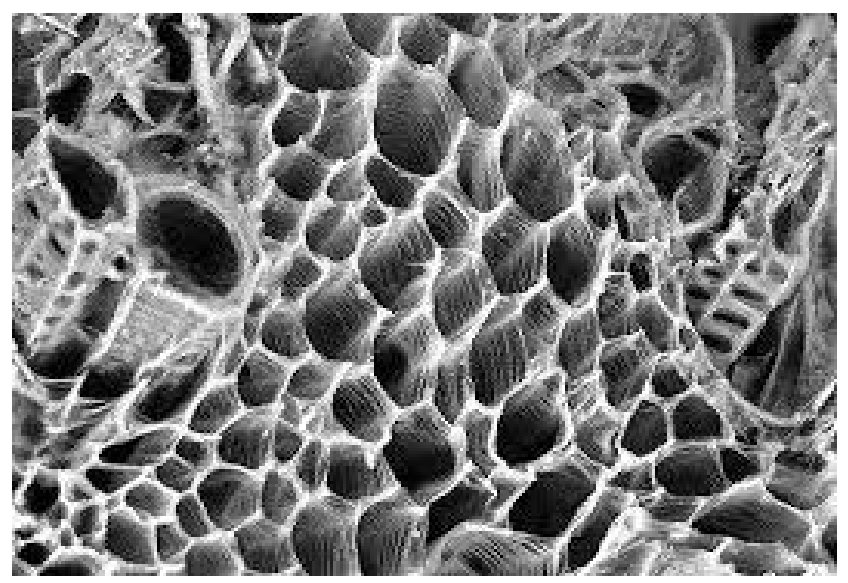

Figure 13: Scanning Electron Microscopy (SEM) image (scale $100(\mathrm{~nm})$ ) of Multi-Walled Carbon Nanotubes (MWCNTs) as the adsorbent for eliminating carcinoma, sarcoma, lymphoma, leukemia, germ cell tumor and blastoma cancer cells and tissues in human blood.

A stock solution of Hydron, Transhumanism, $\mathrm{H}$

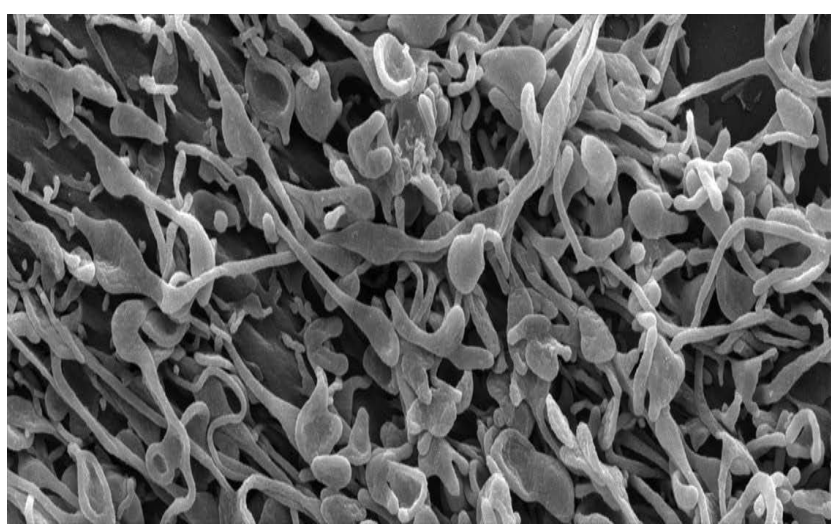

Figure 14: Scanning Electron Microscopy (SEM) image (scale $100(\mathrm{~nm})$ ) of Boron Nitride Nanotubes (BNNTs) as the adsorbent for eliminating carcinoma, sarcoma, lymphoma, leukemia, germ cell tumor and blastoma cancer cells and tissues in human blood.

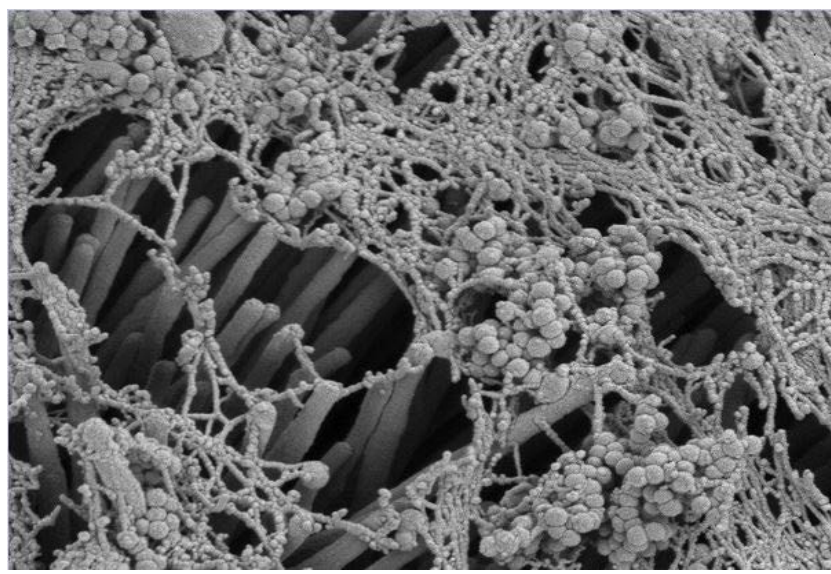

Figure 15: Scanning Electron Microscopy (SEM) image (scale $100(\mathrm{~nm})$ ) of Amorphous Boron Nitride Nanotubes (a-BNNTs) as the adsorbent for eliminating carcinoma, sarcoma, lymphoma, leukemia, germ cell tumor and blastoma cancer cells and tissues in human blood.

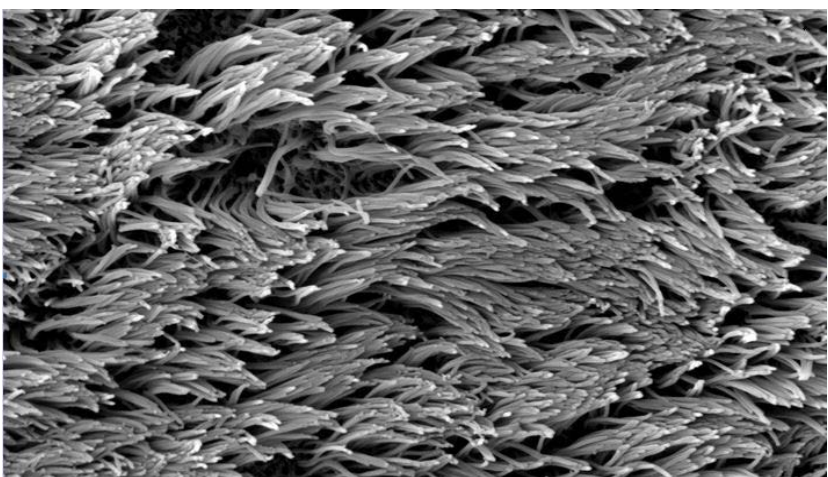

Figure 16: Scanning Electron Microscopy (SEM) image (scale $100(\mathrm{~nm})$ ) of Hexagonal Boron Nitride Nanotubes (h-BNNTs) as the adsorbent for eliminating carcinoma, sarcoma, lymphoma, leukemia, germ cell tumor and blastoma cancer cells and tissues in human blood.

(S-train), Humanity ${ }^{+}$(Humanity Plus), electron hole and Evolved High Speed Packet Access (or HSPA ${ }^{+}$or HSPA (Plus) or HSPAP) was prepared by adding specific amounts of Cadmium Oxide ( $\mathrm{CdO}$ ) nanoparticles to 


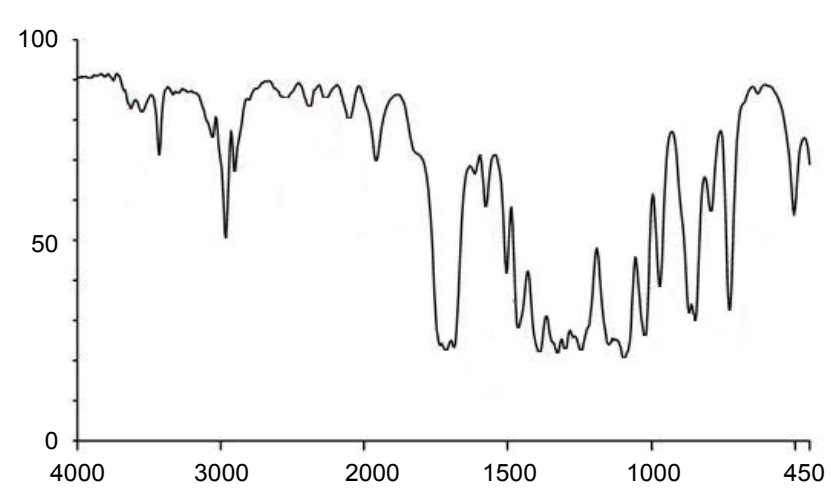

Figure 17: Attenuated Total Reflectance Fourier Transform Infrared (ATR-FTIR) spectrum of Multi-Walled Carbon Nanotubes (MWCNTs) as the adsorbent for eliminating carcinoma, sarcoma, lymphoma, leukemia, germ cell tumor and blastoma cancer cells and tissues in human blood. It should be noted that $y$-axis shows absorbance and also $x$-axis shows wavenumber $\left(\mathrm{cm}^{-1}\right)$.

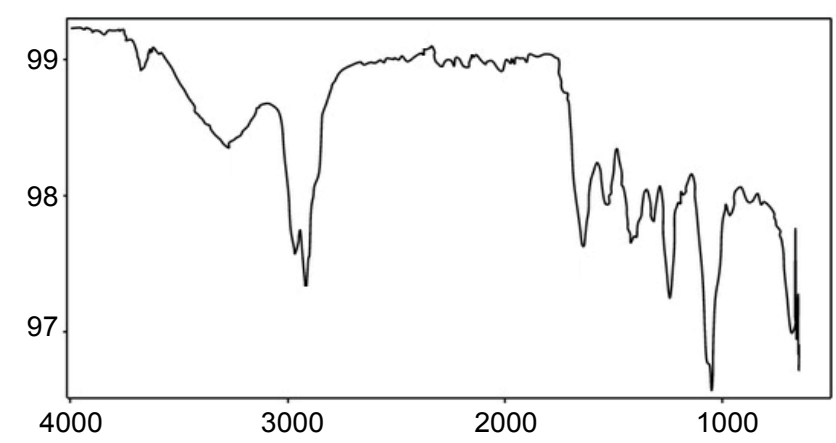

Figure 18: Attenuated Total Reflectance Fourier Transform Infrared (ATR-FTIR) spectrum of Boron Nitride Nanotubes (BNNTs) as the adsorbent for eliminating carcinoma, sarcoma, lymphoma, leukemia, germ cell tumor and blastoma cancer cells and tissues in human blood. It should be noted that $y$-axis shows absorbance and also $x$-axis shows wave number $\left(\mathrm{cm}^{-1}\right)$.

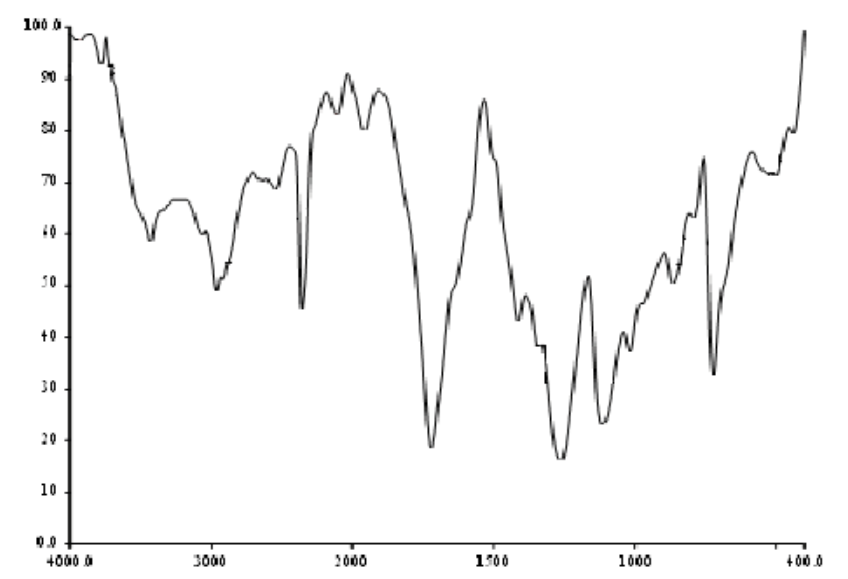

Figure 19: Attenuated Total Reflectance Fourier Transform Infrared (ATR-FTIR) spectrum of Amorphous Boron Nitride Nanotubes (a-BNNTs) as the adsorbent for eliminating carcinoma, sarcoma, lymphoma, leukemia, germ cell tumor and blastoma cancer cells and tissues in human blood. It should be noted that $y$-axis shows absorbance and also $x$-axis shows wave number $\left(\mathrm{cm}^{-1}\right)$.

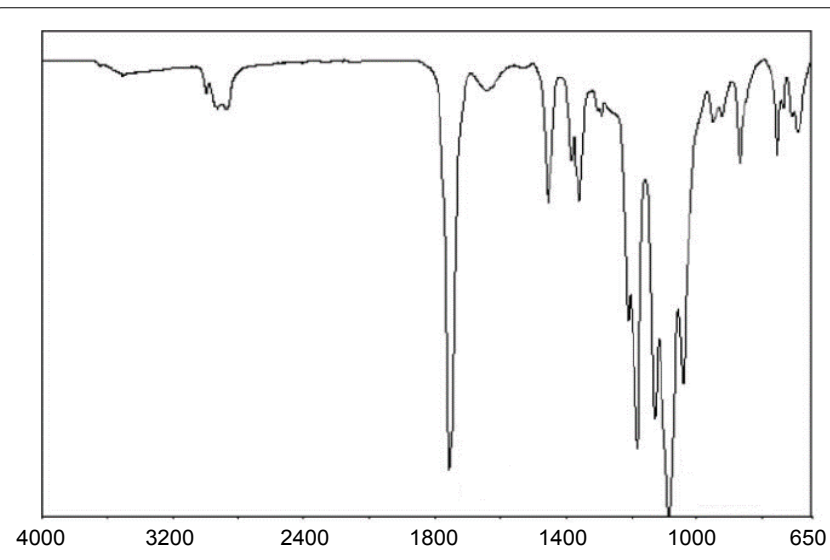

Figure 20: Attenuated Total Reflectance Fourier Transform Infrared (ATR-FTIR) spectrum of Hexagonal Boron Nitride Nanotubes (h-BNNTs) as the adsorbent for eliminating carcinoma, sarcoma, lymphoma, leukemia, germ cell tumor and blastoma cancer cells and tissues in human blood. It should be noted that $y$-axis shows absorbance and also $x$-axis shows wave number $\left(\mathrm{cm}^{-1}\right)$.

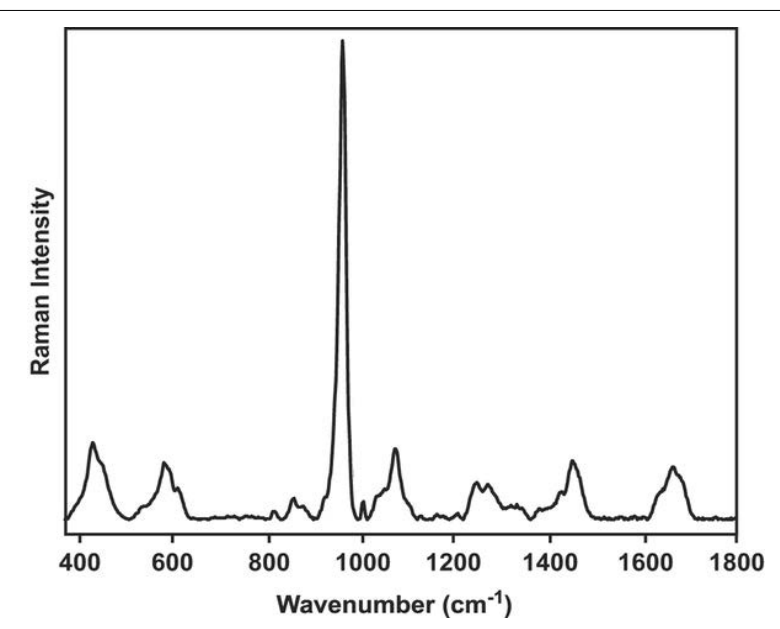

Figure 21: Raman spectrum of Multi-Walled Carbon Nanotubes (MWCNTs) as the adsorbent for eliminating carcinoma, sarcoma, lymphoma, leukemia, germ cell tumor and blastoma cancer cells and tissues in human blood. It should be noted that $y$-axis shows Raman intensity and also $x$-axis shows Raman shift $\left(\mathrm{cm}^{-1}\right)$.

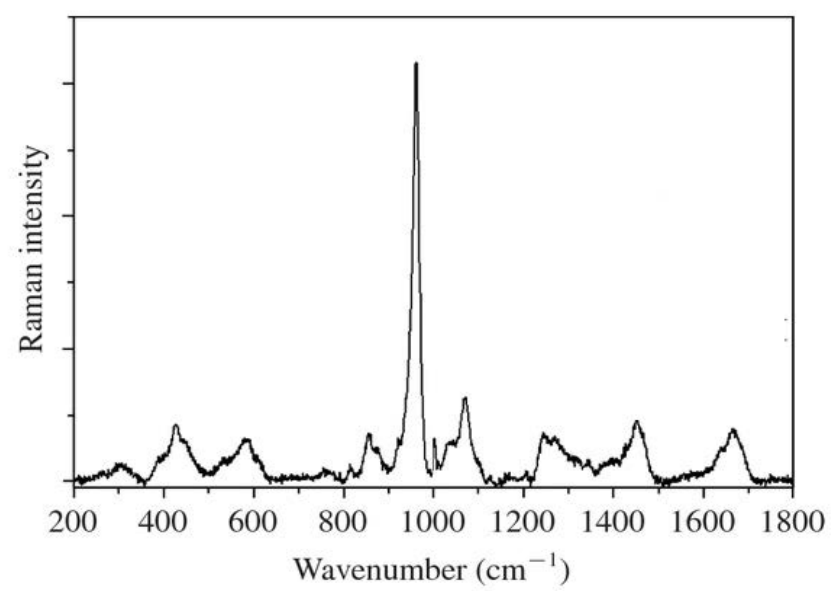

Figure 22: Raman spectrum of Boron Nitride Nanotubes (BNNTs) as the adsorbent for eliminating carcinoma, sarcoma, lymphoma, leukemia, germ cell tumor and blastoma cancer cells and tissues in human blood. It should be noted that $y$-axis shows Raman intensity and also $x$-axis shows Raman shift $\left(\mathrm{cm}^{-1}\right)$. 


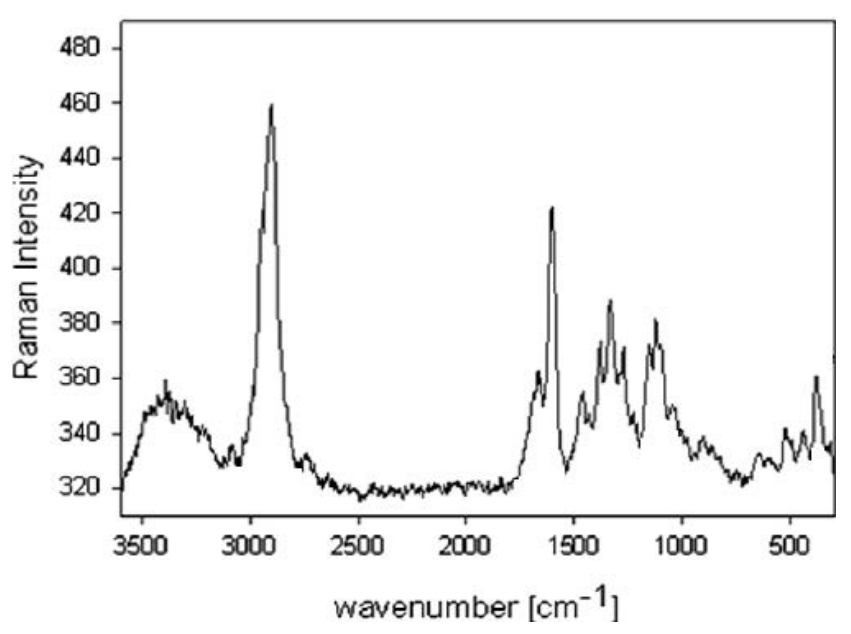

Figure 23: Raman spectrum of Amorphous Boron Nitride Nanotubes (a-BNNTs) as the adsorbent for eliminating carcinoma, sarcoma, lymphoma, leukemia, germ cell tumor and blastoma cancer cells and tissues in human blood. It should be noted that $y$-axis shows Raman intensity and also $x$-axis shows Raman shift $\left(\mathrm{cm}^{-1}\right)$.

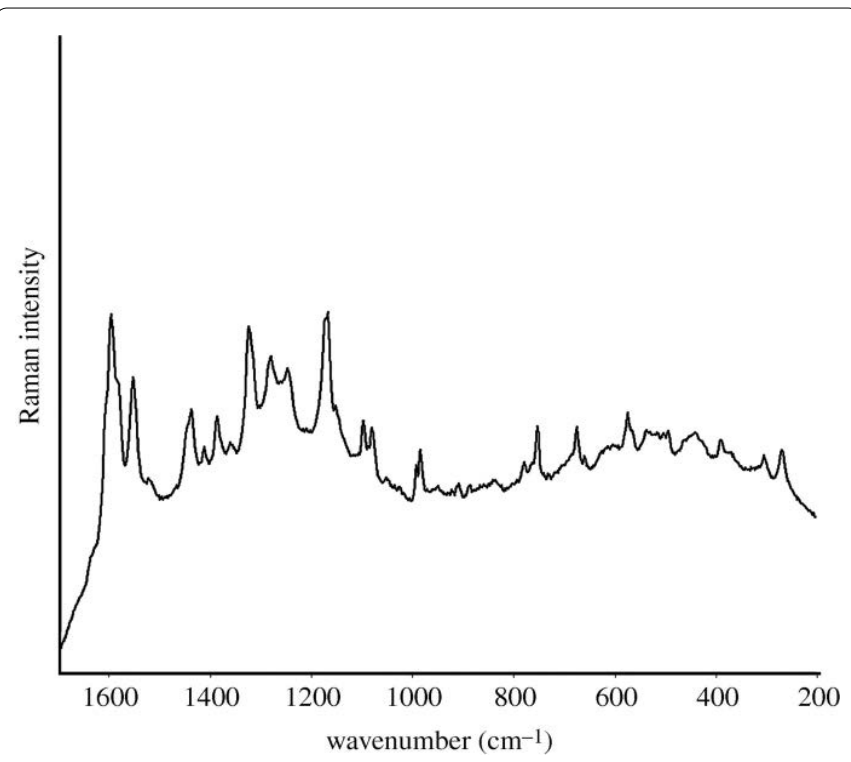

Figure 24: Raman spectrum of Hexagonal Boron Nitride Nanotubes (h-BNNTs) as the adsorbent for eliminating carcinoma, sarcoma, lymphoma, leukemia, germ cell tumor and blastoma cancer cells and tissues in human blood. It should be noted that $y$-axis shows Raman intensity and also $x$-axis shows Raman shift $\left(\mathrm{cm}^{-1}\right)$.

deionized human blood cancer cells and tissues. Next, drinking blood standards as well as human blood cancer cells and tissues standards for discharge into surface human blood cancer cells and tissues were considered during preparation of samples at concentrations of 0.05 , $0.1,0.15$, and $0.2 \mathrm{mg} / \mathrm{L}$ using the synthesized mother solution. The experiments were conducted at different adsorption times and $\mathrm{pHs}$.

Following measurement of the initial levels of Hydron, Transhumanism, H (S-train), Humanity (Humanity Plus), electron hole and Evolved High Speed Packet Access (or $\mathrm{HSPA}^{+}$or HSPA (Plus) or HSPAP) in the human blood cancer cells and tissues, the Multi-Walled Carbon

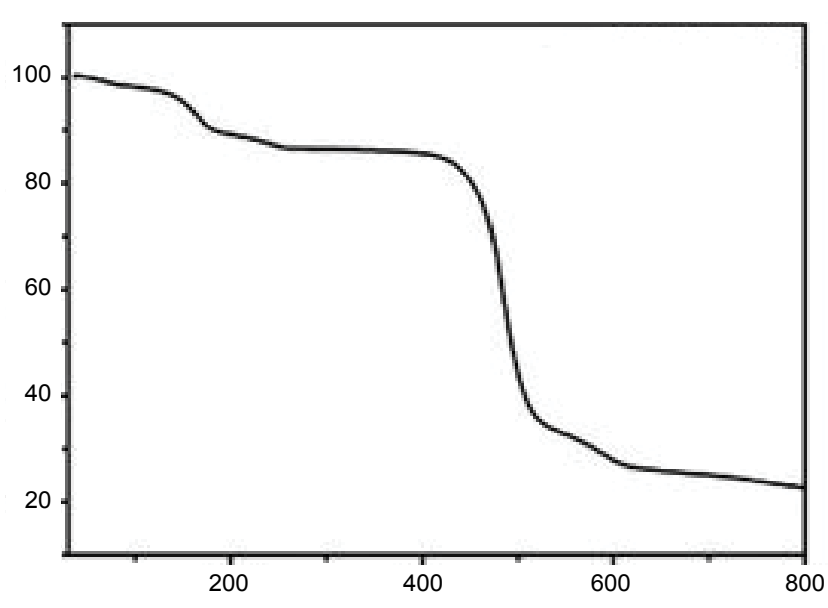

Figure 25: Differential Thermal Analysis-Thermal Gravim Analysis (DTA-TGA) of Multi-Walled Carbon Nanotubes (MWCNTs) as the adsorbent for eliminating carcinoma, sarcoma, lymphoma, leukemia, germ cell tumor and blastoma cancer cells and tissues in human blood. It should be noted that $y$-axis shows weight $(\%)$ and also $x$-axis shows temperature $\left({ }^{\circ} \mathrm{C}\right)$.

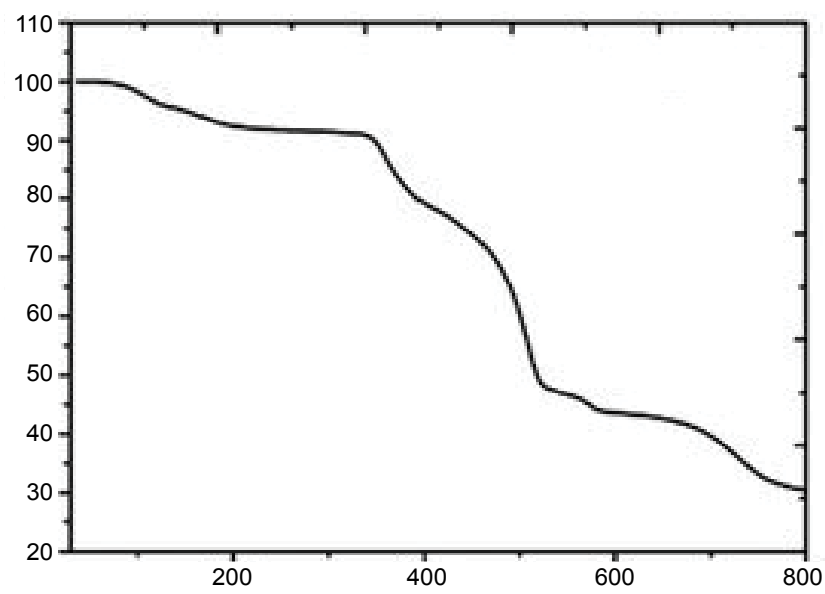

Figure 26: Differential Thermal Analysis-Thermal Gravim Analysis (DTA-TGA) of Boron Nitride Nanotubes (BNNTs) as the adsorbent for eliminating carcinoma, sarcoma, lymphoma, leukemia, germ cell tumor and blastoma cancer cells and tissues in human blood. It should be noted that $y$-axis shows weight $(\%)$ and also $\mathrm{x}$-axis shows temperature $\left({ }^{\circ} \mathrm{C}\right)$.

Nanotubes (MWCNTs), Boron Nitride Nanotubes (BNNTs), Amorphous Boron Nitride Nanotubes (a-BNNTs) and Hexagonal Boron Nitride Nanotubes (h-BNNTs) were brought into contact with the samples for 60,120 , 180 , and $240(\mathrm{~min})$ for the initial concentrations of Hydron, Transhumanism, $\mathrm{H}$ (S-train), Humanity ${ }^{+}$(Humanity Plus), electron hole and Evolved High Speed Packet Access (or HSPA ${ }^{+}$or HSPA (Plus) or HSPAP) $(0.05,0.1,0.15$, and $0.2 \mathrm{mg} / \mathrm{L}), \mathrm{pH}(3,6,9$ and 12$)$ and adsorbent mass $(0.05,0.1,0.15$, and $0.2 \mathrm{ppm}$ of sample). After completion of specific contact times between adsorbent and sample, the human blood cancer cells and tissues from the synchrotronic reactor was sampled. After separation of the adsorbent values, the concentration of Hydron, Transhumanism, H (S-train), Humanity ${ }^{+}$(Humanity Plus), electron hole and Evolved High Speed Packet Ac- 


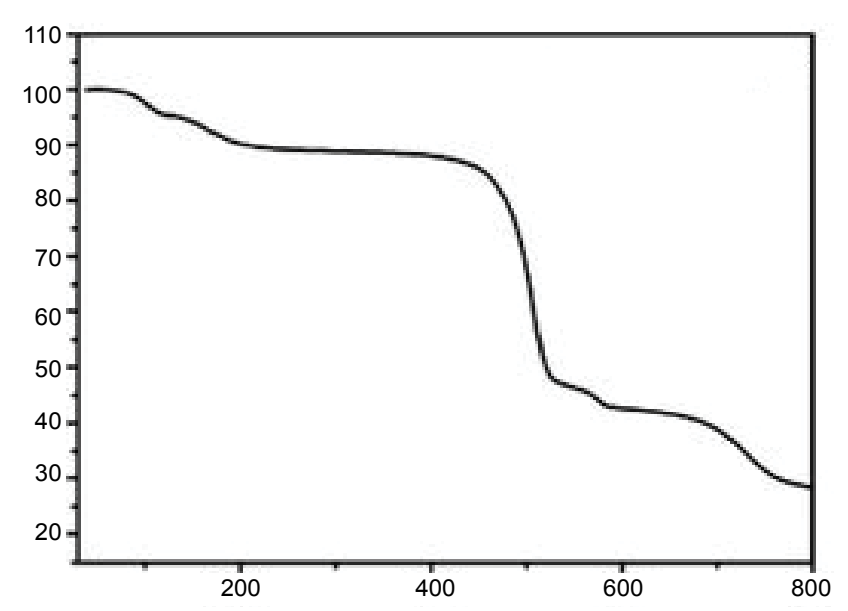

Figure 27: Differential Thermal Analysis-Thermal Gravim Analysis (DTA-TGA) of Amorphous Boron Nitride Nanotubes (a-BNNTs) as the adsorbent for eliminating carcinoma, sarcoma, lymphoma, leukemia, germ cell tumor and blastoma cancer cells and tissues in human blood. It should be noted that $y$-axis shows weight $(\%)$ and also $x$-axis shows temperature $\left({ }^{\circ} \mathrm{C}\right)$.

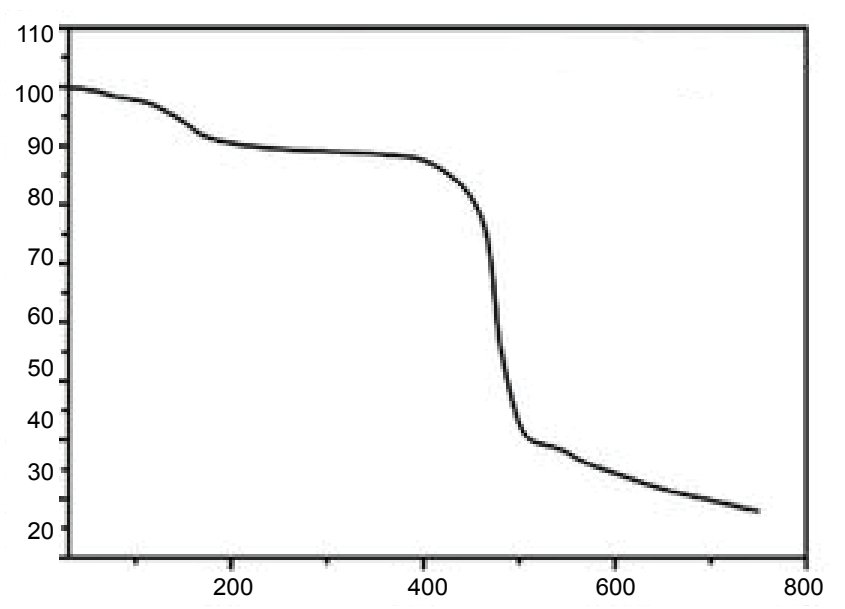

Figure 28: Differential Thermal Analysis-Thermal Gravim Analysis (DTA-TGA) of Hexagonal Boron Nitride Nanotubes (h-BNNTs) as the adsorbent for eliminating carcinoma, sarcoma, lymphoma, leukemia, germ cell tumor and blastoma cancer cells and tissues in human blood. It should be noted that $\mathrm{y}$-axis shows weight (\%) and also $\mathrm{x}$-axis shows temperature $\left({ }^{\circ} \mathrm{C}\right)$.

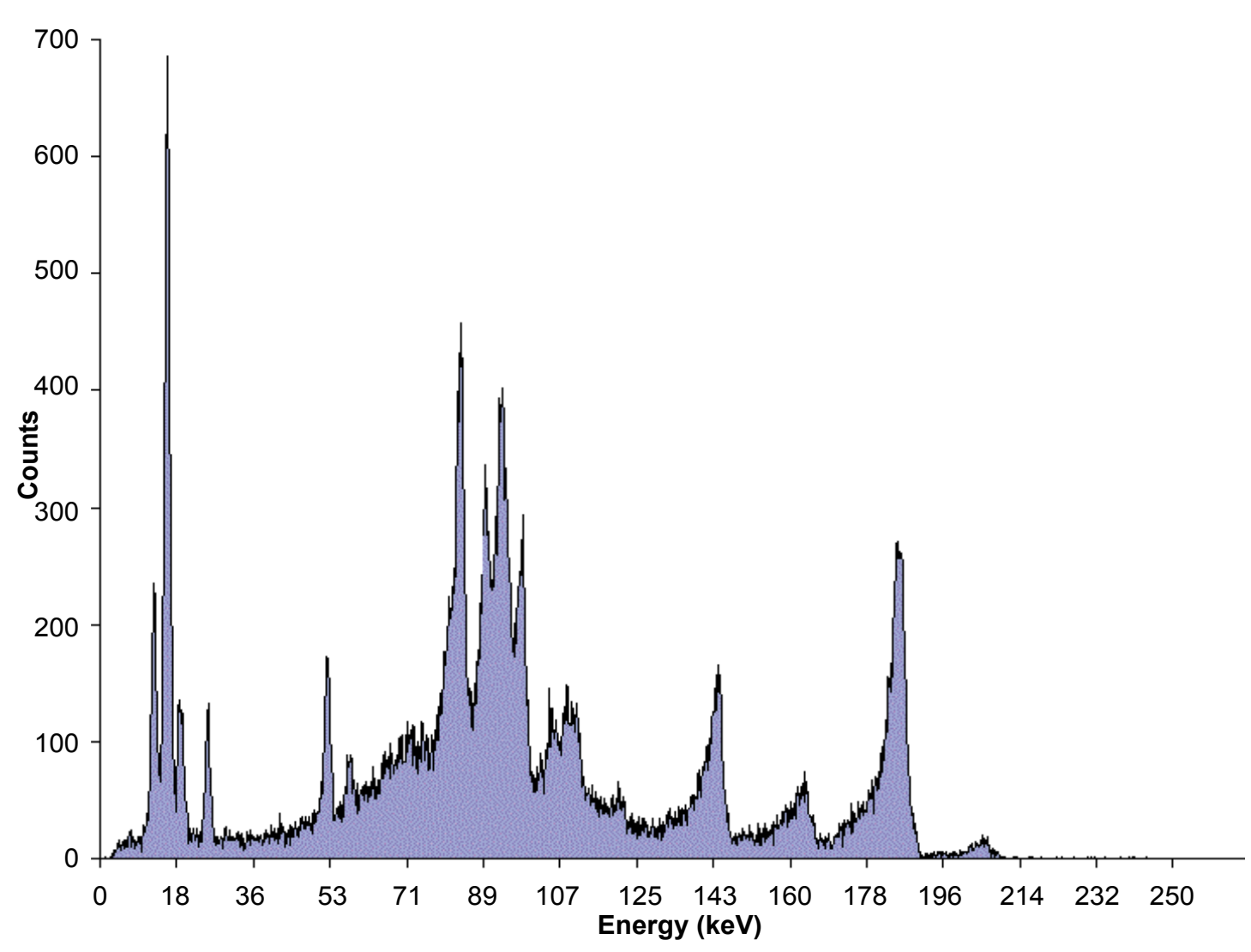

Figure 29: Energy-Dispersive X-Ray (EDX) spectrum of Multi-Walled Carbon Nanotubes (MWCNTs) as the adsorbent for eliminating carcinoma, sarcoma, lymphoma, leukemia, germ cell tumor and blastoma cancer cells and tissues in human blood. It should be noted that $y$-axis shows intensity (counts) and also x-axis shows energy (eV).

cess (or HSPA+ or HSPA (Plus) or HSPAP) was measured using Cadmium Oxide (CdO) nanoparticles according to the standard methods at a wavelength of $590(\mathrm{~nm})$ using a spectrophotometric device. The efficiency of the method was calculated as:

$$
\mathrm{RE} \%=\frac{\mathrm{C}_{0}-\mathrm{C}_{\mathrm{t}}}{\mathrm{N}} \times 100
$$

where $\mathrm{C}_{0}$ and $\mathrm{C}_{t}$ denote the initial and final concentrations of Hydron, Transhumanism, $\mathrm{H}$ (S-train), Humanity ${ }^{+}$ (Humanity Plus), electron hole and Evolved High Speed Packet Access (or $\mathrm{HSPA}^{+}$or HSPA (Plus) or HSPAP) in human blood cancer cells and tissues $(\mathrm{mg} / \mathrm{L})$, respectively and $\mathrm{RE}$ denotes removal efficiency percentage.

The experimental results were evaluated using pseu- 


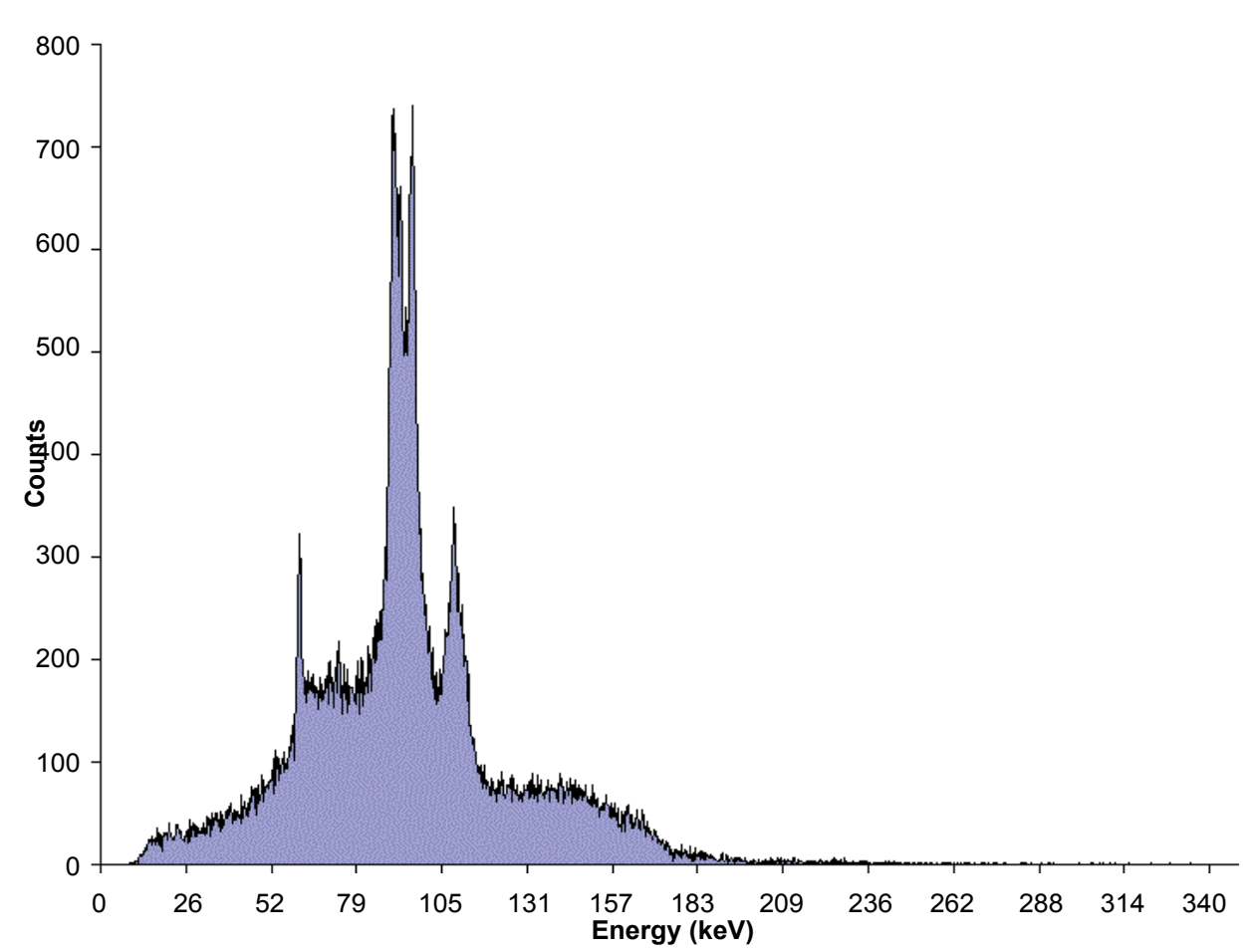

Figure 30: Energy-Dispersive X-Ray (EDX) spectrum of Boron Nitride Nanotubes (BNNTs) as the adsorbent for eliminating carcinoma, sarcoma, lymphoma, leukemia, germ cell tumor and blastoma cancer cells and tissues in human blood. It should be noted that $y$-axis shows intensity (counts) and also x-axis shows energy (eV).

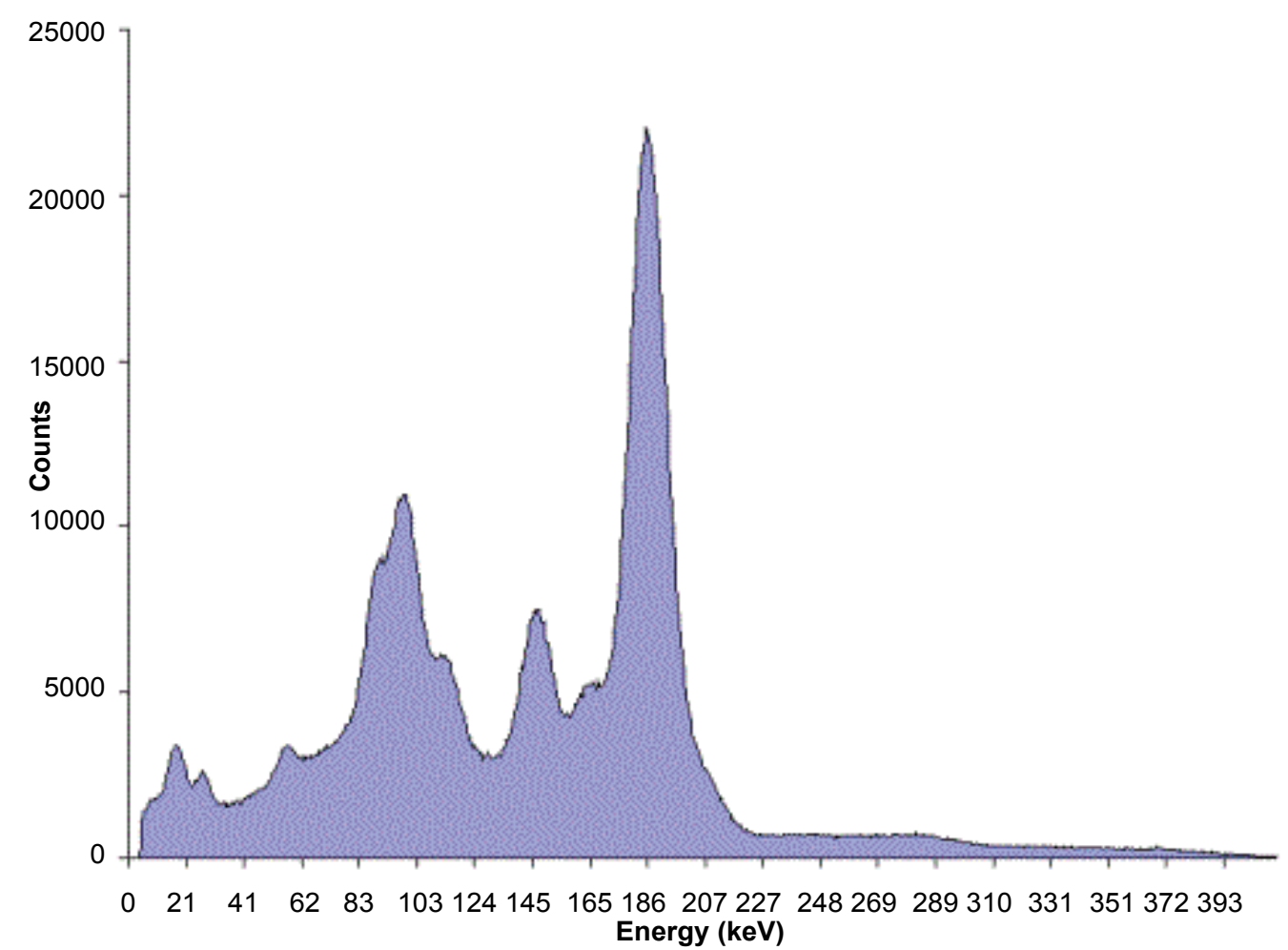

Figure 31: Energy-Dispersive X-Ray (EDX) spectrum of Amorphous Boron Nitride Nanotubes (a-BNNTs) as the adsorbent for eliminating carcinoma, sarcoma, lymphoma, leukemia, germ cell tumor and blastoma cancer cells and tissues in human blood. It should be noted that $\mathrm{y}$-axis shows intensity (counts) and also x-axis shows energy (eV).

do-first-order and pseudo-second-order kinetic models. The adsorption equilibrium conditions were determined by considering $\mathrm{pH}$, adsorbent concentration and concentration of adsorbate, contact time and temperature. The isotherm of equilibrium adsorption was exam- ined using the Langmuir, Freundlich and Tamkin models of Multi-Walled Carbon Nanotubes (MWCNTs), Boron Nitride Nanotubes (BNNTs), Amorphous Boron Nitride Nanotubes (a-BNNTs) and Hexagonal Boron Nitride Nanotubes (h-BNNTs) (Figure 33). 


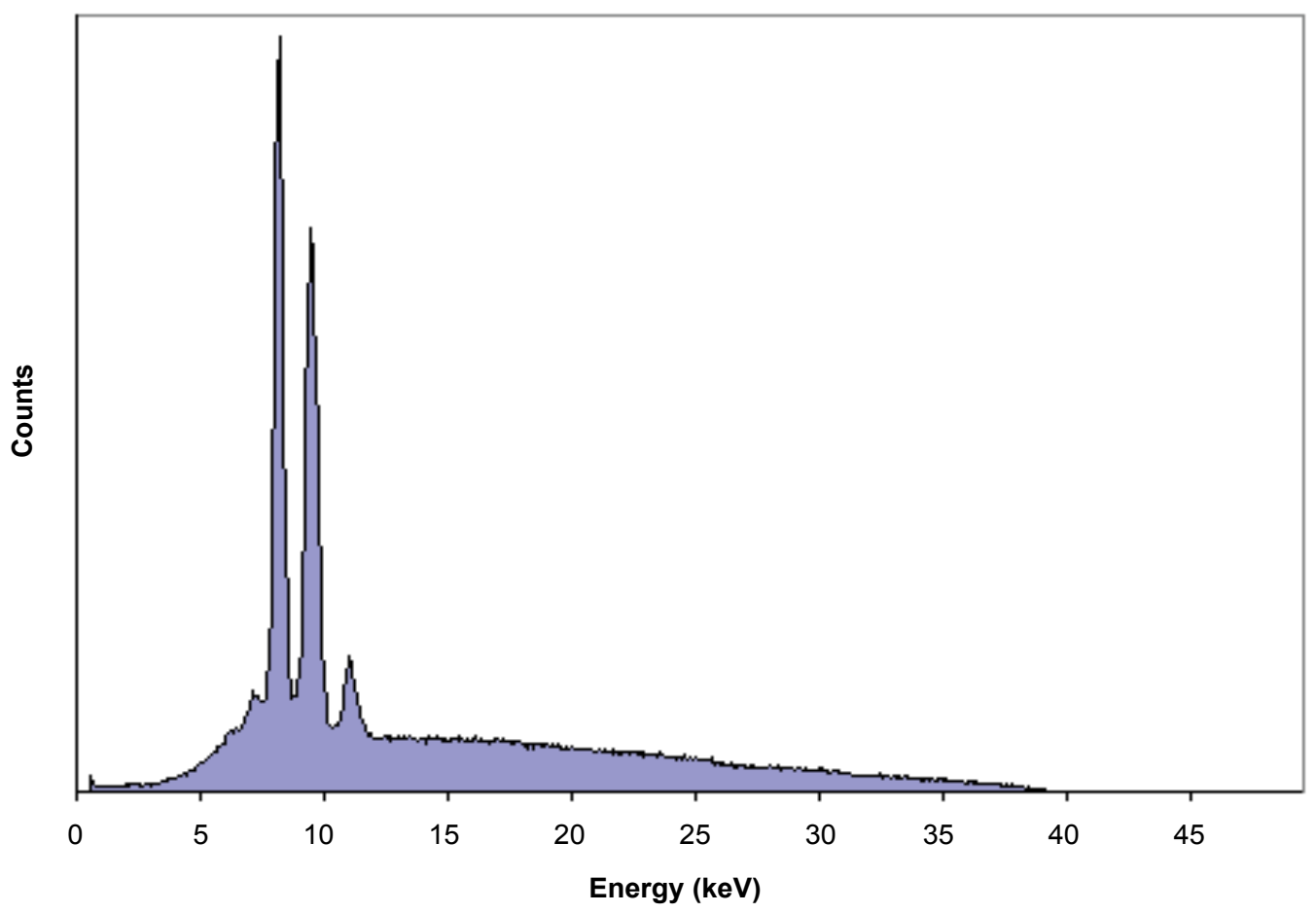

Figure 32: Energy-Dispersive X-Ray (EDX) spectrum of Hexagonal Boron Nitride Nanotubes (h-BNNTs) as the adsorbent for eliminating carcinoma, sarcoma, lymphoma, leukemia, germ cell tumor and blastoma cancer cells and tissues in human blood. It should be noted that $\mathrm{y}$-axis shows intensity (counts) and also x-axis shows energy (eV).

(a)

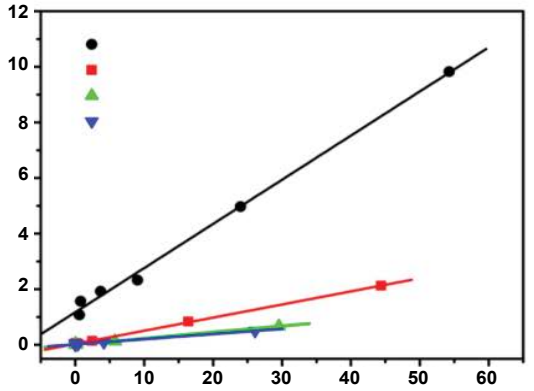

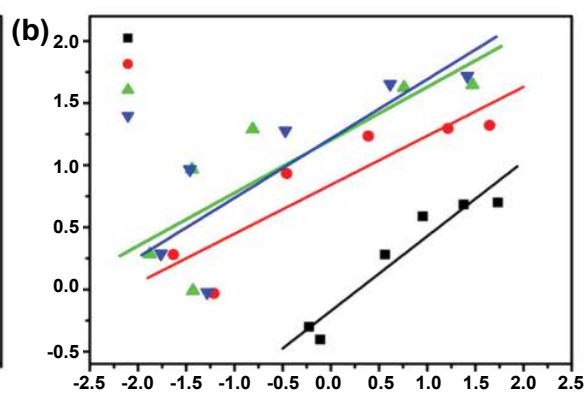

Figure 33: Isotherm models for adsorption: (a) Langmuir, (b) Freundlich and (c) Tamkin of Multi-Walled Carbon Nanotubes (MWCNTs) (black points), Boron Nitride Nanotubes (BNNTs) (red points), Amorphous Boron Nitride Nanotubes (a-BNNTs) (green points) and Hexagonal Boron Nitride Nanotubes (h-BNNTs) (blue points). It should be noted that y-axis shows qe $(\mathrm{mg} / \mathrm{g})$ and also $\mathrm{x}$-axis shows $\mathrm{Ce}(\mathrm{mg} / \mathrm{L})$.

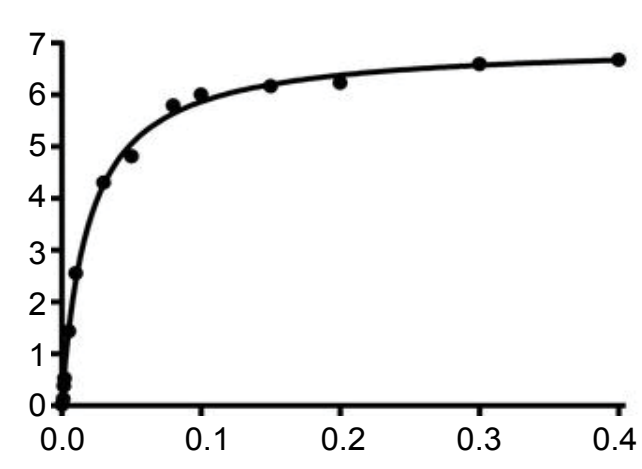

Figure 34: Effect of $\mathrm{pH}$ on adsorption of Hydron, Transhumanism, $\mathrm{H}$ (S-train), Humanity ${ }^{+}$(Humanity Plus), electron hole and Evolved High Speed Packet Access (or HSPA ${ }^{+}$ or HSPA (Plus) or HSPAP) by Multi-Walled Carbon Nanotubes (MWCNTs) for 240 (min), $25{ }^{\circ} \mathrm{C}$, initial Hydron, Transhumanism, H (S-train), Humanity ${ }^{+}$(Humanity Plus), electron hole and Evolved High Speed Packet Access (or $\mathrm{HSPA}^{+}$or HSPA (Plus) or HSPAP) concentration of $0.0001 \mathrm{mg} / \mathrm{L}$ and $0.05 \mathrm{mg} / \mathrm{L}$ of adsorbent. (c)

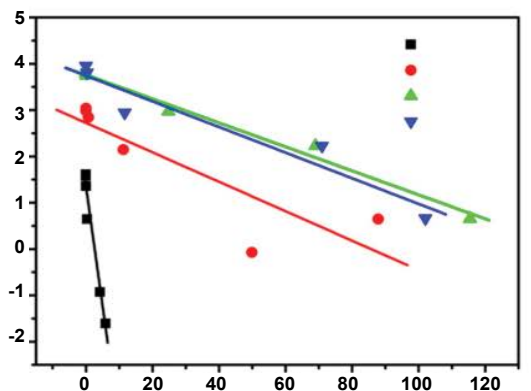




\section{Results and Discussion}

The $\mathrm{pH}$ of an adsorbent solution plays an important role in the process and capacity of adsorption. It affects the superficial charge of the adsorbent and influences the degree of ionization of the toxic compounds in human blood cancer cells and tissues, separation of functional groups onto the adsorption sites and the chemistry of the human blood cancer cells and tissues. The effect of $\mathrm{pH}$ on the adsorption of Hydron, Transhumanism, $\mathrm{H}$ (S-train), Humanity ${ }^{+}$(Humanity Plus), electron hole and Evolved High Speed Packet Access (or HSPA ${ }^{+}$ or HSPA (Plus) or HSPAP) $(0.05 \mathrm{mg} / \mathrm{L}$ of Hydron, Transhumanism, $\mathrm{H}$ (S-train), Humanity ${ }^{+}$(Humanity Plus), electron hole and Evolved High Speed Packet Access (or $\mathrm{HSPA}^{+}$or HSPA (Plus) or HSPAP) and $0.0001 \mathrm{mg} / \mathrm{L}$ of Multi-Walled Carbon Nanotubes (MWCNTs), Boron Nitride Nanotubes (BNNTs), Amorphous Boron Nitride Nanotubes (a-BNNTs) and Hexagonal Boron Nitride

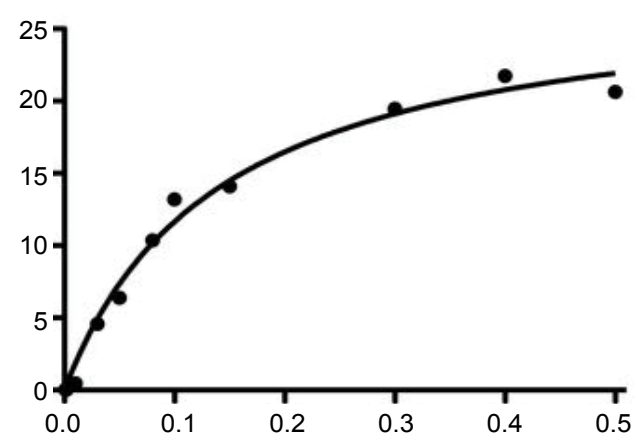

Figure 36: Effect of $\mathrm{pH}$ on adsorption of Hydron, Transhumanism, $\mathrm{H}$ (S-train), Humanity ${ }^{+}$(Humanity Plus), electron hole and Evolved High Speed Packet Access (or HSPA or HSPA (Plus) or HSPAP) by Amorphous Boron Nitride Nanotubes (a-BNNTs) for 240 (min), $25^{\circ} \mathrm{C}$, initial Hydron, Transhumanism, H (S-train), Humanity ${ }^{+}$(Humanity Plus), electron hole and Evolved High Speed Packet Access (or $\mathrm{HSPA}^{+}$or HSPA (Plus) or HSPAP) concentration of $0.0001 \mathrm{mg} / \mathrm{L}$ and $0.05 \mathrm{mg} / \mathrm{L}$ of adsorbent

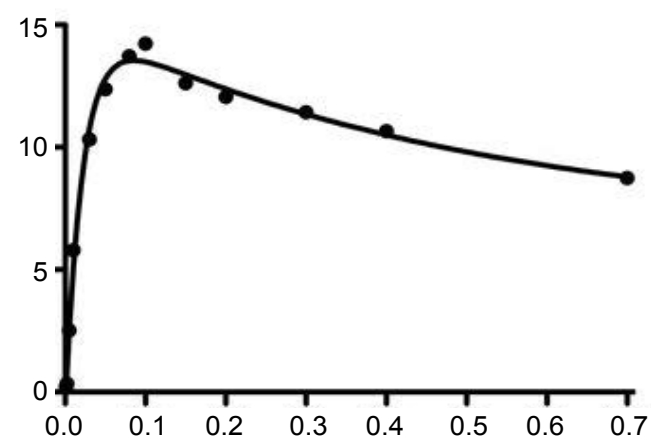

Figure 37: Effect of $\mathrm{pH}$ on adsorption of Hydron, Transhumanism, H (S-train), Humanity ${ }^{+}$(Humanity Plus), electron hole and Evolved High Speed Packet Access (or HSPA ${ }^{+}$ or HSPA (Plus) or HSPAP) by Hexagonal Boron Nitride Nanotubes (h-BNNTs) for 240 ( $\min$ ), $25^{\circ} \mathrm{C}$, initial Hydron, Transhumanism, H (S-train), Humanity ${ }^{+}$(Humanity Plus), electron hole and Evolved High Speed Packet Access (or $\mathrm{HSPA}^{+}$or HSPA (Plus) or HSPAP) concentration of $0.0001 \mathrm{mg} / \mathrm{L}$ and $0.05 \mathrm{mg} / \mathrm{L}$ of adsorbent.
Nanotubes (h-BNNTs) for eliminating carcinoma, sarcoma, lymphoma, leukemia, germ cell tumor and blastoma cancer cells and tissues from human blood after 240 (min) at $\mathrm{pH}$ values of 3, 6, 9 and 12 are shown in Figure 34, Figure 35 , Figure 36 and Figure 37. As shown, an increase in the $\mathrm{pH}$ of the solution from 3 to 6 increased Hydron, Transhumanism, H (S-train), Humanity ${ }^{+}$(Humanity Plus), electron hole and Evolved High Speed Packet Access (or $\mathrm{HSPA}^{+}$or HSPA (Plus) or HSPAP) removal efficiency, but a further increase from 6 to 12 , decreased efficiency.

The effect of the amount of adsorbent $(0.05,0.1,0.15$, and $0.2 \mathrm{mg} / \mathrm{L}$ ) on Hydron, Transhumanism, $\mathrm{H}$ (S-train), Humanity ${ }^{+}$(Humanity Plus), electron hole and Evolved High Speed Packet Access (or HSPA ${ }^{+}$or HSPA (Plus) or HSPAP) removal efficiency by Multi-Walled Carbon Nanotubes (MWCNTs), Boron Nitride Nanotubes (BNNTs), Amorphous Boron Nitride Nanotubes (a-BNNTs) and Hexagonal Boron Nitride Nanotubes (h-BNNTs) for eliminating carcinoma, sarcoma, lymphoma, leukemia, germ cell tumor and blastoma cancer cells and tissues from human blood was investigated in a human blood solution of $0.0001 \mathrm{mg} / \mathrm{L}$ of Hydron, Transhumanism, $\mathrm{H}$ (S-train), Humanity ${ }^{+}$(Humanity Plus), electron hole and Evolved High Speed Packet Access (or HSPA ${ }^{+}$or HSPA (Plus) or HSPAP) at a pH of 6 . The results are shown in Figure 38, Figure 39, Figure 40 and Figure 41. As shown, an increase in absorbent adsorbent dose from 0.05 to 0.2 increased removal of Hydron, Transhumanism, $\mathrm{H}$ (S-train), Humanity ${ }^{+}$(Humanity Plus), electron hole and Evolved High Speed Packet Access (or HSPA ${ }^{+}$or HSPA (Plus) or HSPAP) from $0.81 \%$ to $0.84 \%$.

The effect of the initial concentration of Hydron, Transhumanism, $\mathrm{H}$ (S-train), Humanity ${ }^{+}$(Humanity Plus), electron hole and Evolved High Speed Packet Access (or $\mathrm{HSPA}^{+}$or HSPA (Plus) or HSPAP) $(0.05,0.1,0.15$ and

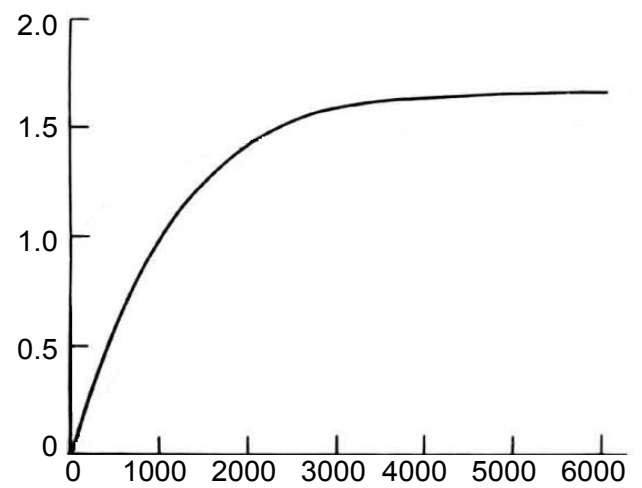

Figure 38: Effect of adsorbent dose on removal of inorganic Hydron, Transhumanism, H (S-train), Humanity ${ }^{+}$ (Humanity Plus), electron hole and Evolved High Speed Packet Access (or HSPA ${ }^{+}$or HSPA (Plus) or HSPAP) using Multi-Walled Carbon Nanotubes (MWCNTs) at 240 (min), $\mathrm{pH}=6$ and $25{ }^{\circ} \mathrm{C}$ for $0.0001 \mathrm{mg} / \mathrm{L}$ of Hydron, Transhumanism, $\mathrm{H}$ (S-train), Humanity ${ }^{+}$(Humanity Plus), electron hole and Evolved High Speed Packet Access (or HSPA ${ }^{+}$ or HSPA (Plus) or HSPAP). 


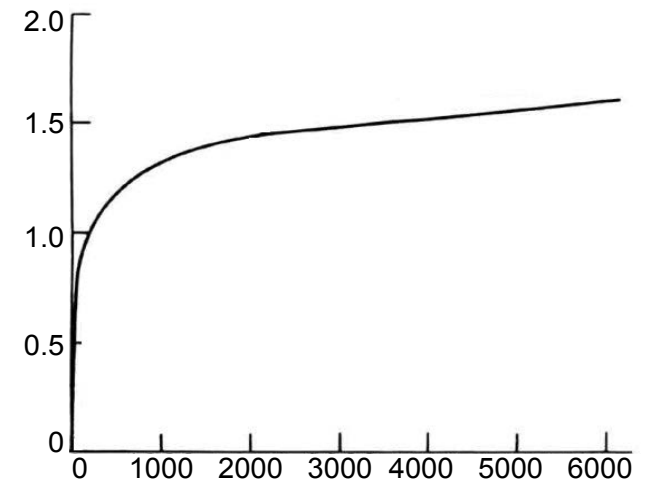

Figure 39: Effect of adsorbent dose on removal of inorganic Hydron, Transhumanism, $\mathrm{H}$ (S-train), Humanity ${ }^{+}$(Humanity Plus), electron hole and Evolved High Speed Packet Access (or $\mathrm{HSPA}^{+}$or HSPA (Plus) or HSPAP) using Boron Nitride Nanotubes (BNNTs) at $240(\mathrm{~min}), \mathrm{pH}=6$ and $25{ }^{\circ} \mathrm{C}$ for $0.0001 \mathrm{mg} / \mathrm{L}$ of Hydron, Transhumanism, $\mathrm{H}$ (S-train), Humanity $^{+}$(Humanity Plus), electron hole and Evolved High Speed Packet Access (or HSPA+ or HSPA (Plus) or HSPAP).

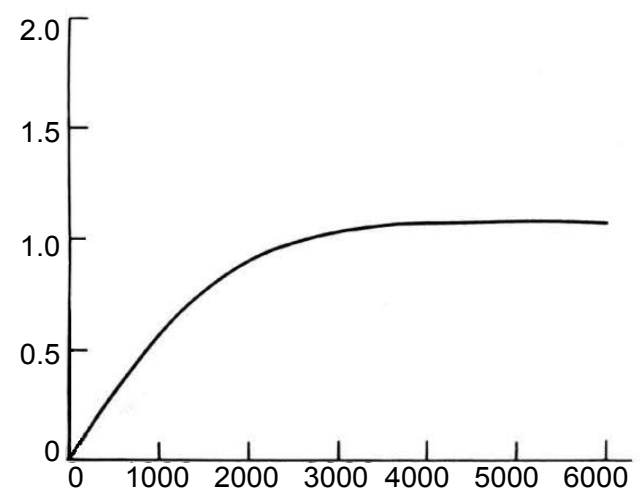

Figure 40: Effect of adsorbent dose on removal of inorganic Hydron, Transhumanism, $\mathrm{H}$ (S-train), Humanity ${ }^{+}$(Humanity Plus), electron hole and Evolved High Speed Packet Access (or $\mathrm{HSPA}^{+}$or HSPA (Plus) or HSPAP) using Amorphous Boron Nitride Nanotubes (a-BNNTs) at 240 (min), $\mathrm{pH}=6$ and $25^{\circ} \mathrm{C}$ for $0.0001 \mathrm{mg} / \mathrm{L}$ of Hydron, Transhumanism, $\mathrm{H}$ (S-train), Humanity ${ }^{+}$(Humanity Plus), electron hole and Evolved High Speed Packet Access (or $\mathrm{HSPA}^{+}$ or HSPA (Plus) or HSPAP).

$0.2 \mathrm{mg} / \mathrm{L}$ ) on Hydron, Transhumanism, H (S-train), Humanity ${ }^{+}$(Humanity Plus), electron hole and Evolved High Speed Packet Access (or HSPA+ or HSPA (Plus) or HSPAP) removal efficiency at $\mathrm{pH}=6$ for different contact times is shown in Figure 42, Figure 43, Figure 44 and Figure 45. As shown, an increase in the initial concentration of $\mathrm{Hy}$ dron, Transhumanism, $\mathrm{H}$ (S-train), Humanity ${ }^{+}$(Humanity Plus), electron hole and Evolved High Speed Packet Access (or $\mathrm{HSPA}^{+}$or HSPA (Plus) or HSPAP) from 0.05 to 0.2 $\mathrm{mg} / \mathrm{L}$ increased removal efficiency from $0.54 \%$ to $0.91 \%$.

It is essential to determine the factors affecting the reaction rate and mechanisms controlling adsorption, including adsorption at the surface, chemical reaction and diffusion mechanisms through kinetic evaluation. Pseudo-first-order and pseudo-second-order kinetic models are widely used to characterize adsorption. A pseudo-first-order kinetic model indicates that diffusion

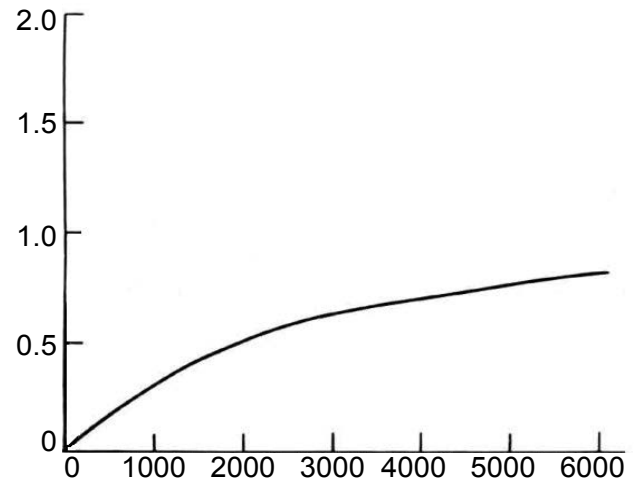

Figure 41: Effect of adsorbent dose on removal of inorganic Hydron, Transhumanism, $\mathrm{H}$ (S-train), Humanity ${ }^{+}$(Humanity Plus), electron hole and Evolved High Speed Packet Access (or $\mathrm{HSPA}^{+}$or HSPA (Plus) or HSPAP) using Hexagonal Boron Nitride Nanotubes (h-BNNTs) at 240 (min), pH $=6$ and $25^{\circ} \mathrm{C}$ for $0.0001 \mathrm{mg} / \mathrm{L}$ of Hydron, Transhumanism, $\mathrm{H}$ (S-train), Humanity ${ }^{+}$(Humanity Plus), electron hole and Evolved High Speed Packet Access (or $\mathrm{HSPA}^{+}$or HSPA (Plus) or HSPAP).

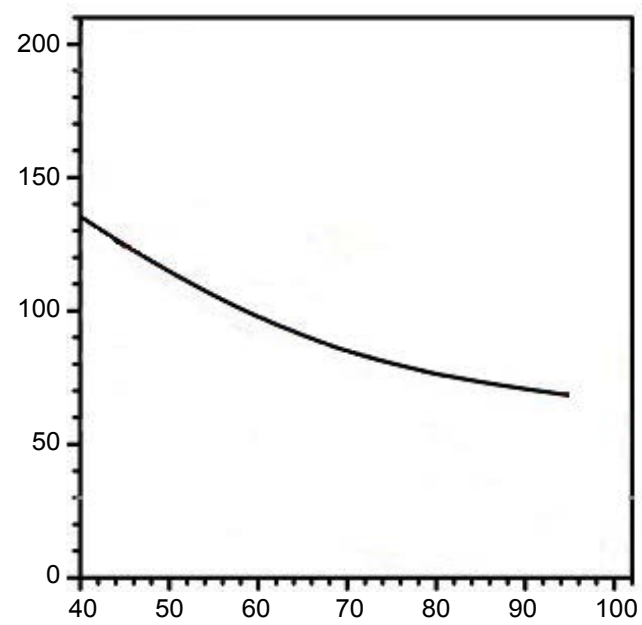

Figure 42: Effect of initial concentration of Hydron, Transhumanism, $\mathrm{H}$ (S-train), Humanity ${ }^{+}$(Humanity Plus), electron hole and Evolved High Speed Packet Access (or HSPA ${ }^{+}$ or HSPA (Plus) or HSPAP) on adsorption by Multi-Walled Carbon Nanotubes (MWCNTs) at 240 (min), $\mathrm{pH}=6$ and 25 ${ }^{\circ} \mathrm{C}$ for $0.0001 \mathrm{mg} / \mathrm{L}$ of adsorbent.

takes place from inside a layer and is based on solid capacity. A pseudo-second-order kinetic model indicates that chemical adsorption slows the rate and controls adsorption, which is based on solid phase adsorption. The linear form of the pseudo-first-order kinetic model is expressed by following Eq. (2):

$$
\log \left(q_{e}-q_{t}\right)=\log \left(q_{e}\right)-\left(\frac{k_{1}}{2.303}\right) t
$$

Where $q_{e}$ is denotes the equilibrium adsorption Hydron, Transhumanism, $\mathrm{H}$ (S-train), Humanity ${ }^{+}$(Humanity Plus), electron hole and Evolved High Speed Packet Access (or $\mathrm{HSPA}^{+}$or HSPA (Plus) or HSPAP) onto the by Multi-Walled Carbon Nanotubes (MWCNTs), Boron Nitride Nanotubes (BNNTs), Amorphous Boron Nitride Nanotubes (a-BNNTs) and Hexagonal Boron Nitride 
Table 1: Pseudo-first-order and pseudo-second-order kinetic models at $\mathrm{pH}=6, \mathrm{~T}=25^{\circ} \mathrm{C}$ for $0.0001 \mathrm{mg} / \mathrm{L}$ of adsorbent which show the values for $\mathrm{q}_{\mathrm{e}}, \mathrm{K}_{1}, \mathrm{~K}_{2}$ and $\mathrm{R}^{2}$ (correlation coefficient) at different Hydron, Transhumanism, $\mathrm{H}$ (S-train), Humanity ${ }^{+}$(Humanity Plus), electron hole and Evolved High Speed Packet Access (or HSPA ${ }^{+}$or HSPA (Plus) or HSPAP) concentrations (0.05 - 0.2 mg/L).

\begin{tabular}{|l|l|l|l|l|l|l|l|}
\hline & \multicolumn{3}{|c|}{ Pseudo-First Order } & \multicolumn{3}{|c|}{ Pseudo-Second Order } \\
\hline $\mathbf{C}_{\text {solution(mg/L) }}$ & $\left(\mathbf{q}_{\mathbf{e}}\right)_{\text {Exp. }}$ & $\left(\mathbf{q}_{\mathbf{e}}\right)_{\text {Cal. }}$ & $\mathbf{k}_{\mathbf{1}}$ & $\mathbf{R}_{\mathbf{1}}{ }^{\mathbf{2}}$ & $\left.\mathbf{( q}_{\mathbf{e}}\right)_{\text {Cal. }}$ & $\mathbf{k}_{\mathbf{2}}$ & $\mathbf{R}_{\mathbf{2}}{ }^{\mathbf{2}}$ \\
\hline 0.05 & 2.5 & 1 & 4 & 0.9 & 0 & 442.5 & 0.5 \\
\hline 0.1 & 31 & 7.5 & 24.5 & 0.9 & 0 & 413 & 0.5 \\
\hline 0.15 & 15 & 8 & 15 & 0.9 & 0 & 420.5 & 0.5 \\
\hline 0.2 & 21.5 & 12 & 27.5 & 0.9 & 0 & 430.5 & 0.5 \\
\hline
\end{tabular}

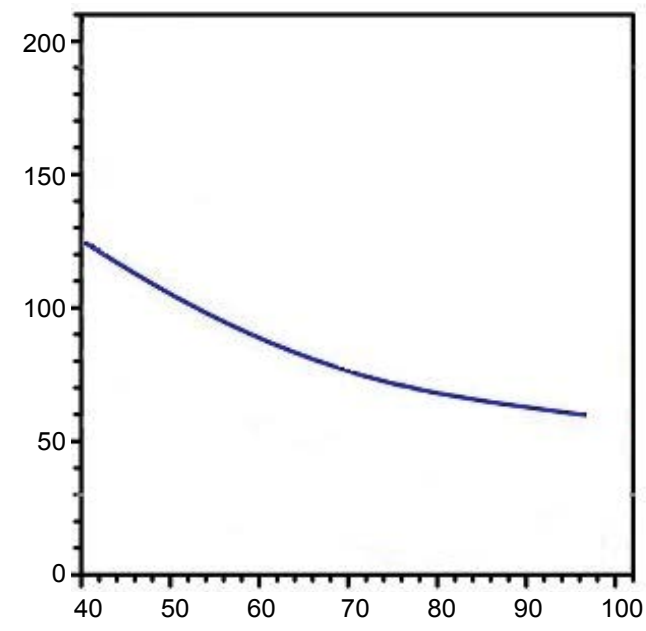

Figure 43: Effect of initial concentration of Hydron, Transhumanism, $\mathrm{H}$ (S-train), Humanity ${ }^{+}$(Humanity Plus), electron hole and Evolved High Speed Packet Access (or HSPA ${ }^{+}$ or HSPA (Plus) or HSPAP) on adsorption by Boron Nitride Nanotubes (BNNTs) at $240(\mathrm{~min}), \mathrm{pH}=6$ and $25^{\circ} \mathrm{C}$ for $0.0001 \mathrm{mg} / \mathrm{L}$ of adsorbent.

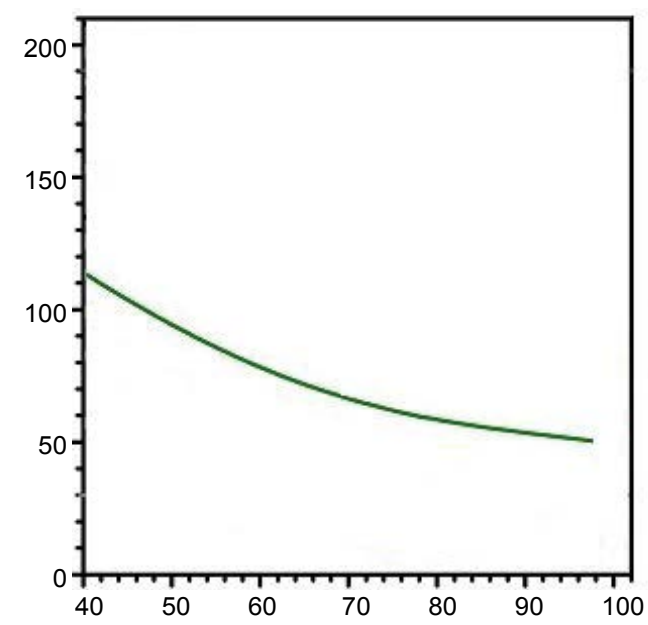

Figure 44: Effect of initial concentration of Hydron, Transhumanism, $\mathrm{H}$ (S-train), Humanity ${ }^{+}$(Humanity Plus), electron hole and Evolved High Speed Packet Access (or HSPA or HSPA (Plus) or HSPAP) on adsorption by Amorphous Boron Nitride Nanotubes (a-BNNTs) at 240 (min), pH = 6 and $25^{\circ} \mathrm{C}$ for $0.0001 \mathrm{mg} / \mathrm{L}$ of adsorbent.

Nanotubes (h-BNNTs) (mg. $\left.\mathrm{g}^{-1}\right), \mathrm{q}_{\mathrm{t}}$ denotes the amount of adsorption Hydron, Transhumanism, $\mathrm{H}$ (S-train), Humanity ${ }^{+}$(Humanity Plus), electron hole and Evolved High Speed Packet Access (or HSPA ${ }^{+}$or HSPA (Plus) or HSPAP) adsorbed at time $(\mathrm{t})\left(\mathrm{mg} \cdot \mathrm{g}^{-1}\right)$ and $\mathrm{k}_{1}$ denotes the equilibrium constant of the first-order kinetic rate $\left(\mathrm{min}^{-1}\right)$. The

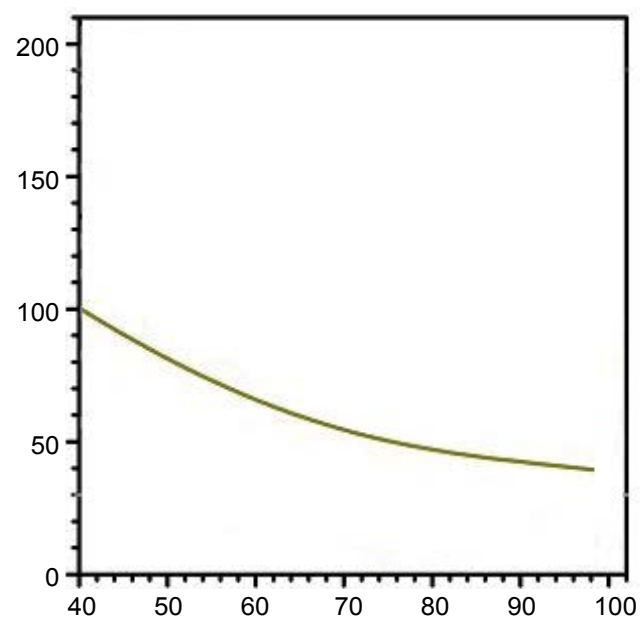

Figure 45: Effect of initial concentration of Hydron, Transhumanism, $\mathrm{H}$ (S-train), Humanity ${ }^{+}$(Humanity Plus), electron hole and Evolved High Speed Packet Access (or HSPA ${ }^{+}$ or HSPA (Plus) or HSPAP) on adsorption by Hexagonal Boron Nitride Nanotubes (h-BNNTs) at 240 (min), $\mathrm{pH}=6$ and $25^{\circ} \mathrm{C}$ for $0.0001 \mathrm{mg} / \mathrm{L}$ of adsorbent.

linear form of the pseudo-second-order kinetic model is:

$$
\frac{t}{q_{t}}=\frac{1}{k_{2} q_{e}^{2}}+\left(\frac{1}{q_{e}}\right) t
$$

Where $\mathrm{q}_{\mathrm{e}}$ represents the equilibrium adsorption $\mathrm{Hy}$ dron, Transhumanism, H (S-train), Humanity ${ }^{+}$(Humanity Plus), electron hole and Evolved High Speed Packet Access (or HSPA ${ }^{+}$or HSPA (Plus) or HSPAP) $\left(\mathrm{mg}^{-1} \mathrm{~g}^{-1}\right), \mathrm{q}_{t}$ denotes the adsorption capacity Hydron, Transhumanism, $\mathrm{H}$ (S-train), Humanity ${ }^{+}$(Humanity Plus), electron hole and Evolved High Speed Packet Access (or HSPA or HSPA (Plus) or HSPAP) at time $t$ (mg. $\mathrm{g}^{-1}$ ) and $\mathrm{k}_{2}$ denotes the equilibrium constant of the first-order kinetic rate $\left(\mathrm{g} \cdot \mathrm{mg}^{-1} \cdot \mathrm{min}^{-1}\right)$.

Table 1 shows the values for $\mathrm{q}_{\mathrm{e}^{\prime}} \mathrm{K}_{1}, \mathrm{~K}_{2}$ and $\mathrm{R}^{2}$ (correlation coefficient) at different Hydron, Transhumanism, $\mathrm{H}$ (S-train), Humanity (Humanity Plus), electron hole and Evolved High Speed Packet Access (or $\mathrm{HSPA}^{+}$or HSPA (Plus) or HSPAP) concentrations (0.05- $0.2 \mathrm{mg} / \mathrm{L}$ ). Comparison of the correlation coefficients of these equations shows that the degree of adherence at adsorption equilibrium to the pseudo-second-order kinetics is greatest.

Adsorption isotherms were used to describe how the contaminants react with adsorbents. Isotherms define the relationship among the Hydron, Transhumanism, $\mathrm{H}$ (S-train), Humanity ${ }^{+}$(Humanity Plus), electron hole and Evolved High Speed Packet Access (or HSPA ${ }^{+}$or HSPA 
(Plus) or HSPAP) adsorbed at a constant temperature with the adsorbent mass at equilibrium. The Langmuir, Freundlich and Tamkin models were used to determine the mechanism, superficial characteristics and adsorption tendency of experimental data at equilibrium. In the Langmuir model, adsorption takes place at a series of sites inside the adsorbent. The linear form of this equation is:

$$
\frac{C_{e}}{q_{e}}=\frac{1}{K_{L} Q_{0}}+\frac{C_{e}}{Q_{0}}
$$

Where $\mathrm{q}_{\mathrm{e}}$ denotes the amount of Hydron, Transhumanism, $\mathrm{H}$ (S-train), Humanity ${ }^{+}$(Humanity Plus), electron hole and Evolved High Speed Packet Access (or $\mathrm{HSPA}^{+}$or HSPA (Plus) or HSPAP) adsorbed onto the Multi-Walled Carbon Nanotubes (MWCNTs), Boron Nitride Nanotubes (BNNTs), Amorphous Boron Nitride Nanotubes (a-BNNTs) and Hexagonal Boron Nitride Nanotubes (h-BNNTs)mg/g, $C_{e}$ denotes the final equilibrium concentration of the solution $(\mathrm{mg} / \mathrm{l}), \mathrm{K}_{\mathrm{L}}$ denotes the equilibrium constant Langmuir and $\mathrm{Q}_{0}$ denotes the maximum adsorption capacity at monolayer coverage $(\mathrm{mg} / \mathrm{L})$. The main characteristic of the Langmuir isotherm is the curved shape of the isotherm, a dimensionless constant called the equilibrium parameter ( $R L$ ) which it can be represented by the following Eq. (5):

$$
\mathrm{R}_{\mathrm{L}}=1 /\left(1+\mathrm{K}_{\mathrm{L}} \mathrm{C}_{0}\right)
$$

Where $K_{L}$ is the Langmuir constant $(L / m g), C_{0}$ is the initial concentration of Hydron, Transhumanism, $\mathrm{H}$ (S-train), Humanity (Humanity Plus), electron hole and Evolved High Speed Packet Access (or HSPA ${ }^{+}$or HSPA (Plus) or HSPAP) and $R_{L}$ is the value indicate the type of isotherm; $R_{L}=0$ is irreversible, $0<R_{L}<1$ is favorable, and $1<R_{L}$ is unfavorable.
In the Freundlich (1906) isotherm, adsorption occurs in response to the heterogeneous surface having a non-uniform distribution of adsorption heat on the surface. It can be liner expressed as follows:

$$
\log \mathrm{q}_{\mathrm{e}}=\log \mathrm{K}_{\mathrm{F}}+\frac{1}{n} \log \mathrm{C}_{\mathrm{e}}
$$

Where $K_{F}$ is the adsorption capacity at unit concentration and $1 / \mathrm{n}$ is the intensity of adsorption and indicates the type of isotherm; $1 / n=0$ is irreversible, $0<1 / n$ $<1$ is desirable and $1 / n>0$ is undesirable.

The Tamkin isotherm assumes that the adsorption heat of all nanomolecules in a layer declines linearly due to the interaction between the adsorbent and the adsorbate. This model describes the interaction between the adsorbent and adsorbate and is expressed as:

$$
\mathrm{q}_{\mathrm{e}}=\mathrm{B}_{1} \ln \mathrm{K}_{\mathrm{T}}+\mathrm{B}_{1} \ln \mathrm{C}_{\mathrm{e}}
$$

Where $B_{1}=R T / b, K_{T}$ is the adsorption capacity at unit concentration and $C_{e}$ is the concentration of the solution at equilibrium.

The isotherm constants and correlation coefficients of adsorption of Hydron, Transhumanism, $\mathrm{H}$ (S-train), Humanity ${ }^{+}$(Humanity Plus), electron hole and Evolved High Speed Packet Access (or HSPA ${ }^{+}$or HSPA (Plus) or HSPAP) by Multi-Walled Carbon Nanotubes (MWCNTs), Boron Nitride Nanotubes (BNNTs), Amorphous Boron Nitride Nanotubes (a-BNNTs) and Hexagonal Boron Nitride Nanotubes (h-BNNTs) are shown in Table 2, Table 3, Table 4 and Table 5. The results indicate that the adsorption of Hydron, Transhumanism, $\mathrm{H}$ (S-train), Humanity ${ }^{+}$(Humanity Plus), electron hole and Evolved High Speed Packet Access (or HSPA ${ }^{+}$or HSPA (Plus) or HSPAP) onto the adsorbent follows the Langmuir model.

Table 2: Isotherm constants for adsorption by Multi-Walled Carbon Nanotubes (MWCNTs) $\left(\mathrm{pH}=6,240\right.$ (min), $\mathrm{T}=25^{\circ} \mathrm{C}, 0.0001$ $\mathrm{mg} / \mathrm{L}$ of adsorbent).

\begin{tabular}{|c|c|c|c|c|c|c|c|c|c|}
\hline \multicolumn{4}{|c|}{ Langmuir Isotherm } & \multicolumn{3}{|c|}{ Freundlich Isotherm } & \multicolumn{3}{|c|}{ Temkin Isotherm } \\
\hline $\mathbf{Q}_{0}$ & $K_{L}$ & $\mathbf{R}_{\mathrm{L}}$ & $\mathbf{R}_{1}{ }^{2}$ & $\mathbf{K}_{\mathrm{F}}$ & $\mathbf{N}$ & $\mathbf{R}_{2}{ }^{2}$ & $\mathbf{K}_{\mathrm{T}}$ & $B_{1}$ & $\mathbf{R}_{3}{ }^{2}$ \\
\hline 11.67 & 0.16 & 0.18 & 0.90 & 0.693 & 0.50 & 0.90 & 3.27 & 1.93 & 0.90 \\
\hline
\end{tabular}

\begin{tabular}{|l|l|l|l|l|l|l|l|l|l|}
\hline \multicolumn{4}{|l}{ Langmuir Isotherm } & \multicolumn{4}{l|}{ Freundlich Isotherm } & \multicolumn{3}{l|}{ Temkin Isotherm } \\
\hline $\mathbf{Q}_{\mathbf{0}}$ & $\mathbf{K}_{\mathrm{L}}$ & $\mathbf{R}_{\mathbf{L}}$ & $\mathbf{R}_{1}{ }^{\mathbf{2}}$ & $\mathbf{K}_{\mathbf{F}}$ & $\mathbf{N}$ & $\mathbf{R}_{\mathbf{2}}{ }^{2}$ & $\mathbf{K}_{\mathrm{T}}$ & $\mathbf{B}_{\mathbf{1}}$ & $\mathbf{R}_{\mathbf{3}}{ }^{\mathbf{2}}$ \\
\hline 14.25 & 0.14 & 0.16 & 0.90 & 0.529 & 0.50 & 0.90 & 2.90 & 1.45 & 0.90 \\
\hline
\end{tabular}

Table 3: Isotherm constants for adsorption by Boron Nitride Nanotubes (BNNTs) $\left(\mathrm{pH}=6,240(\mathrm{~min}), \mathrm{T}=25^{\circ} \mathrm{C}, 0.0001 \mathrm{mg} / \mathrm{L}\right.$ of adsorbent).

Table 4: Isotherm constants for adsorption by Amorphous Boron Nitride Nanotubes (a-BNNTs) $\left(\mathrm{pH}=6,240(\mathrm{~min}), \mathrm{T}=25^{\circ} \mathrm{C}\right.$, $0.0001 \mathrm{mg} / \mathrm{L}$ of adsorbent).

\begin{tabular}{|c|c|c|c|c|c|c|c|c|c|}
\hline \multicolumn{4}{|c|}{ Langmuir Isotherm } & \multicolumn{3}{|c|}{ Freundlich Isotherm } & \multicolumn{3}{|c|}{ Temkin Isotherm } \\
\hline $\mathbf{Q}_{0}$ & $\mathbf{K}_{\mathrm{L}}$ & $\mathbf{R}_{\mathrm{L}}$ & $\mathbf{R}_{1}{ }^{2}$ & $\mathbf{K}_{\mathrm{F}}$ & $\mathbf{N}$ & $\mathbf{R}_{2}{ }^{2}$ & $\mathbf{K}_{\mathrm{T}}$ & $B_{1}$ & $\mathbf{R}_{3}{ }^{2}$ \\
\hline 13.77 & 0.14 & 0.23 & 0.90 & 0.619 & 0.60 & 0.90 & 3.99 & 2.01 & 0.90 \\
\hline
\end{tabular}

\begin{tabular}{|l|l|l|l|l|l|l|l|l|l|}
\hline \multicolumn{4}{|l}{ Langmuir Isotherm } & \multicolumn{4}{c|}{ Freundlich Isotherm } & \multicolumn{3}{l|}{ Temkin Isotherm } \\
\hline $\mathbf{Q}_{\mathbf{0}}$ & $\mathbf{K}_{\mathbf{L}}$ & $\mathbf{R}_{\mathbf{L}}$ & $\mathbf{R}_{1}{ }^{\mathbf{2}}$ & $\mathbf{K}_{\mathbf{F}}$ & $\mathbf{N}$ & $\mathbf{R}_{\mathbf{2}}{ }^{\mathbf{2}}$ & $\mathbf{K}_{\mathbf{T}}$ & $\mathbf{B}_{\mathbf{1}}$ & $\mathbf{R}_{\mathbf{3}}{ }^{\mathbf{2}}$ \\
\hline 12.84 & 0.15 & 0.19 & 0.90 & 0.514 & 0.65 & 0.90 & 3.83 & 1.97 & 0.90 \\
\hline
\end{tabular}

Table 5: Isotherm constants for adsorption by Hexagonal Boron Nitride Nanotubes (h-BNNTs) $(\mathrm{pH}=6,240$ ( $\mathrm{min})$, $\mathrm{T}=25^{\circ} \mathrm{C}$, $0.0001 \mathrm{mg} / \mathrm{L}$ of adsorbent). 
The results of initial $\mathrm{pH}$ of the solution showed that Hydron, Transhumanism, $\mathrm{H}$ (S-train), Humanity ${ }^{+}$(Humanity Plus), electron hole and Evolved High Speed Packet Access (or $\mathrm{HSPA}^{+}$or HSPA (Plus) or HSPAP) removal efficiency by Multi-Walled Carbon Nanotubes (MWCNTs), Boron Nitride Nanotubes (BNNTs), Amorphous Boron Nitride Nanotubes (a-BNNTs) and Hexagonal Boron Nitride Nanotubes (h-BNNTs) for eliminating carcinoma, sarcoma, lymphoma, leukemia, germ cell tumor and blastoma cancer cells and tissues from human blood was affected by $\mathrm{pH}$ of the solution. Also, results show that an increase in $\mathrm{pH}$ from 3 to 6 increased removal efficiency, but a further increase from 6 to 9 decreased removal efficiency. The reason for the reduction in removal efficiency at acidic $\mathrm{pH}$ values is that, in acidic environments, Hydron, Transhumanism, $\mathrm{H}$ (S-train), Humanity $^{+}$(Humanity Plus), electron hole and Evolved High Speed Packet Access (or HSPA ${ }^{+}$or HSPA (Plus) or HSPAP) are the predominant species of $\mathrm{H}^{+}$. These two species are nearly neutral and do not compete with $\mathrm{H}^{+}$ions for adsorption. In alkaline environments, hydroxyl ions predominate and compete with Hydron, Transhumanism, $\mathrm{H}$ (S-train), Humanity ${ }^{+}$(Humanity Plus), electron hole and Evolved High Speed Packet Access (or HSPA ${ }^{+}$or HSPA (Plus) or HSPAP) for adsorption. These results are congruent with those obtained by Heidari, et al. [21-153].

The effect of adsorbent mass and determination of optimal mass of the adsorbent should be taken into consideration. The results indicate that an increase in adsorbent mass increases the percentage of adsorption Hydron, Transhumanism, H (S-train), Humanity ${ }^{+}$ (Humanity Plus), electron hole and Evolved High Speed Packet Access (or HSPA ${ }^{+}$or HSPA (Plus) or HSPAP). This results in a decrease in the number of available adsorption sites at a constant level of contaminant concentration.

To investigate the effect of the initial concentration of Hydron, Transhumanism, H (S-train), Humanity ${ }^{+}$ (Humanity Plus), electron hole and Evolved High Speed Packet Access (or $\mathrm{HSPA}^{+}$or HSPA (Plus) or HSPAP) on removal efficiency, Hydron, Transhumanism, $\mathrm{H}$ (S-train), Humanity ${ }^{+}$(Humanity Plus), electron hole and Evolved High Speed Packet Access (or HSPA ${ }^{+}$or HSPA (Plus) or HS$\mathrm{PAP}$ ) concentration was varied from 0.05 to $0.2 \mathrm{mg} / \mathrm{L}$. Furthermore, obtained results show that an increase in the initial concentration of Hydron, Transhumanism, $\mathrm{H}$ (S-train), Humanity ${ }^{+}$(Humanity Plus), electron hole and Evolved High Speed Packet Access (or HSPA ${ }^{+}$or HSPA (Plus) or HSPAP) decreased the removal efficiency of Hydron, Transhumanism, H (S-train), Humanity ${ }^{+}$(Humanity Plus), electron hole and Evolved High Speed Packet Access (or $\mathrm{HSPA}^{+}$or HSPA (Plus) or HSPAP). This can be attributed to the decrease in available adsorption sites at saturation. Heidari, et al. found that an increase in Multi-Walled Carbon Nanotubes (MWCNTs), Boron Nitride Nanotubes (BNNTs), Amorphous Boron Nitride Nanotubes (a-BNNTs) and Hexagonal Boron
Nitride Nanotubes (h-BNNTs) modified with Cadmium Oxide (CdO) increased Hydron, Transhumanism, $\mathrm{H}$ (S-train), Humanity ${ }^{+}$(Humanity Plus), electron hole and Evolved High Speed Packet Access (or HSPA ${ }^{+}$or HSPA (Plus) or HSPAP) decreased the removal efficiency of Hydron, Transhumanism, H (S-train), Humanity ${ }^{+}$(Humanity Plus), electron hole and Evolved High Speed Packet Access (or $\mathrm{HSPA}^{+}$or HSPA (Plus) or HSPAP) adsorption [21153]. In addition, Heidari, et al. found that an increase in Hydron, Transhumanism, $\mathrm{H}$ (S-train), Humanity ${ }^{+}$(Humanity Plus), electron hole and Evolved High Speed Packet Access (or $\mathrm{HSPA}^{+}$or HSPA (Plus) or HSPAP) decreased the removal efficiency of Hydron, Transhumanism, $\mathrm{H}$ (S-train), Humanity ${ }^{+}$(Humanity Plus), electron hole and Evolved High Speed Packet Access (or HSPA ${ }^{+}$ or HSPA (Plus) or HSPAP) concentration on hydrotalkite modified with Cadmium Oxide (CdO) decreased Hydron, Transhumanism, H (S-train), Humanity ${ }^{+}$(Humanity Plus), electron hole and Evolved High Speed Packet Access (or $\mathrm{HSPA}^{+}$or HSPA (Plus) or HSPAP) removal efficiency [21-153].

\section{Conclusions, Perspectives and Future Studies}

Adsorption isotherms are mathematical relations used to describe the way of adsorbate reacts with the adsorbent to optimize equilibrium of adsorbent to be used. The adsorption isotherms in this study showed that Hydron, Transhumanism, H (S-train), Humanity $^{+}$(Humanity Plus), electron hole and Evolved High Speed Packet Access (or HSPA ${ }^{+}$or HSPA (Plus) or HSPAP) adsorption onto Multi-Walled Carbon Nanotubes (MWCNTs), Boron Nitride Nanotubes (BNNTs), Amorphous Boron Nitride Nanotubes (a-BNNTs) and Hexagonal Boron Nitride Nanotubes (h-BNNTs) for eliminating carcinoma, sarcoma, lymphoma, leukemia, germ cell tumor and blastoma cancer cells and tissues from human blood was best described by the Langmuir model. This appears to result from the uniform distribution or single layer of active sites on the adsorbent. The results obtained from the reaction kinetics indicated that the adsorption is best described by pseudo-second order kinetics. The correlation coefficient in the pseudo-second order model was greater than for the pseudo-first order model. In addition, the value of $\mathrm{q}_{\mathrm{e}}$ calculated by pseudo-second order kinetics is more similar to the results of the experimental data. It can be concluded and stated that the adsorption kinetics also depend on both the amount of adsorbent and the concentration of the adsorbate.

\section{References}

1. Bastogne T (2017) Quality-by-design of nanopharmaceuticals - a state of the art. Nanomedicine: Nanotechnology, Biology and Medicine 13: 2151-2157.

2. Zeljka Vanic, Natasa Skalko-Basnet (2013) Nanopharmaceuticals for improved topical vaginal therapy: Can they deliver? European Journal of Pharmaceutical Sciences 50: 29-41. 
3. Islan GA, Durán M, Cacicedo ML, Nakazato G, Kobayash RKT, et al. (2017) Nanopharmaceuticals as a solution to neglected diseases: Is it possible? Acta Tropica 170: 16-42.

4. Bawarski WE, Chidlowsky E, Bharali DJ, Mousa SA (2008) Emerging nanopharmaceuticals. Nanomedicine: Nanotechnology, Biology and Medicine 4: 273-282.

5. Eaton MAW (2011) How do we develop nanopharmaceuticals under open innovation? Nanomedicine: Nanotechnology, Biology and Medicine 7: 371-375.

6. Hadinoto K, Yang Y (2014) Continuous and sustainable granulation of nanopharmaceuticals by spray coagulation encapsulation in alginate. International Journal of Pharmaceutics 473: 644-652.

7. Svenson S, Wolfgang M, Hwang J, Ryan J, Eliasof S (2011) Preclinical to clinical development of the novel camptothecin nanopharmaceutical CRLX101. Journal of Controlled Release 153: 49-55.

8. Sosnik A (2013) Reversal of multidrug resistance by the inhibition of ATP-binding cassette pumps employing "Generally Recognized As Safe" (GRAS) nanopharmaceuticals: A review. Advanced Drug Delivery Reviews 65: 1828-1851.

9. Filipović-Grčić J, Mrhar A, Junginger H (2013) Thematic Issue on Emerging nanopharmaceuticals for non-parenteral application routes. European Journal of Pharmaceutical Sciences 50: 1.

10. Yu H, Hadinoto K (2015) Mitigating the adverse effect of spray drying on the supersaturation generation capability of amorphous nanopharmaceutical powders. Powder Technology 277: 97-104.

11. Moghimi SM, Farhangrazi ZS (2013) Nanomedicine and the complement paradigm. Nanomedicine: Nanotechnology, Biology and Medicine 9: 458-460.

12. Eliasof S, Ng PS, Soo PL, Podobinski J, RI Case, et al. (2010) 425 Significantly enhanced therapeutic profile of docetaxel in novel nanopharmaceutical CRLX288. EJC Supplements 8: 135 .

13. Domingo C, Saurina J (2012) An overview of the analytical characterization of nanostructured drug delivery systems: Towards green and sustainable pharmaceuticals: A review. Analytica Chimica Acta 744: 8-22.

14. Samadder A, Abraham SK, Khuda-Bukhsh AR (2016) Nanopharmaceutical approach using pelargonidin towards enhancement of efficacy for prevention of alloxan-induced DNA damage in L6 cells via activation of PARP and p53. Environmental Toxicology and Pharmacology 43: 27-37.

15. Yen Y, Synold T, Weiss GJ, Schluep T, Ryan J (2010) 423 Phase 1 dose escalation, safety and pharmacokinetic study of IT-101 (CRLX101), a novel nanopharmaceutical containing camptothecin, in advanced solid tumor cancer patients. European Journal of Cancer Supplements 8: 134-135.

16. Azmi IDM, Wibroe PP, Wu LP, Kazem Al, Amenitsch $\mathrm{H}$, et al. (2016) A structurally diverse library of safe-by-design citrem-phospholipid lamellar and non-lamellar liquid crystalline nano-assemblies. Journal of Controlled Release 239. $1-9$.

17. Li J, Wang Y, Liang R, An X, Wang K, et al. (2015) Recent advances in targeted nanoparticles drug delivery to melanoma. Nanomedicine: Nanotechnology, Biology and Medicine 11: 769-794.

18. Liu J, Zhao Y, Guo Q, Wang Z, Wang H, et al. (2012) TAT-modified nanosilver for combating multidrug-resistant cancer. Biomaterials 33: 6155-6161.
19. Cristina Gabellieri, Heico Frima (2011) Nanomedicine in the European Commission policy for nanotechnology. Nanomedicine: Nanotechnology, Biology and Medicine 7: 519-520.

20. Robert M Frederickson, SM Moghimi, E Wagner, Seppo Yla-Herttuala (2016) Call for papers: Nanoparticle development and applications in cellular and molecular therapies. Molecular Therapy 24: 1334-1335.

21. Alireza Heidari, Christopher Brown (2015) Study of composition and morphology of cadmium oxide (CdO) nanoparticles for eliminating cancer cells. J Nanomed Res 2: 20.

22. Alireza Heidari, Christopher Brown (2015) Study of surface morphological, phytochemical and structural characteristics of rhodium (III) oxide (Rh2O3) nanoparticles. International Journal of Pharmacology, Phytochemistry and Ethnomedicine 1: 15-19.

23. Alireza Heidari (2016) An experimental biospectroscopic study on seminal plasma in determination of semen quality for evaluation of male infertility. Int J Adv Technol 7: e007.

24. Alireza Heidari (2016) Extraction and preconcentration of $\mathrm{N}$-Tolyl-Sulfonyl-Phosphoramid-Saeure-Dichlorid as an anti-cancer drug from plants: A pharmacognosy study. J Pharmacogn Nat Prod 2: e103.

25. Alireza Heidari (2016) A thermodynamic study on hydration and dehydration of DNA and RNA-amphiphile complexes. J Bioeng Biomed Sci S: 006.

26. Alireza Heidari (2016) Computational studies on molecular structures and carbonyl and ketene groups' effects of singlet and triplet energies of azidoketene $\mathrm{O}=\mathrm{C}=\mathrm{CH}-\mathrm{NNN}$ and isocyanatoketene $\mathrm{O}=\mathrm{C}=\mathrm{CH}-\mathrm{N}=\mathrm{C}=\mathrm{O}$. J Appl Computat Math 5: e142.

27. Alireza Heidari (2016) Study of irradiations to enhance the induces the dissociation of hydrogen bonds between peptide chains and transition from helix structure to random coil structure using ATR-FTIR, Raman and 1HNMR spectroscopies. J Biomol Res Ther 5: e146.

28. Alireza Heidari (2016) Future prospects of point fluorescence spectroscopy, fluorescence imaging and fluorescence endoscopy in photodynamic therapy (PDT) for cancer cells. J Bioanal Biomed 8: e135.

29. Alireza Heidari (2016) A bio-spectroscopic study of DNA density and color role as determining factor for absorbed irradiation in cancer cells. Adv Cancer Prev 1: e102.

30. Alireza Heidari (2016) Manufacturing process of solar cells using Cadmium Oxide ( $\mathrm{CdO}$ ) and Rhodium (III) Oxide (Rh2O3) nanoparticles. J Biotechnol Biomater 6: e125.

31. Alireza Heidari (2016) A novel experimental and computational approach to photobiosimulation of telomeric DNA/ RNA: A biospectroscopic and photobiological study. J Res Development 4: 144.

32. Alireza Heidari (2016) Biochemical and pharmacodynamical study of microporous molecularly imprinted polymer selective for vancomycin, teicoplanin, oritavancin, telavancin and dalbavancin binding. Biochem Physiol 5: e146.

33. Alireza Heidari (2016) Anti-Cancer effect of UV irradiation at presence of cadmium oxide $(\mathrm{CdO})$ nanoparticles on DNA of cancer cells: A photodynamic therapy study. Arch Cancer Res 4: 1.

34. Alireza Heidari (2016) Biospectroscopic study on multi-component reactions (MCRs) in two A-Type and B-Type conformations of nucleic acids to determine ligand binding modes, binding constant and stability of nucleic acids in cadmium 
oxide $(\mathrm{CdO})$ nanoparticles-nucleic acids complexes as anti-cancer drugs. Arch Cancer Res 4: 2.

35. Alireza Heidari (2016) Simulation of temperature distribution of DNA/RNA of human cancer cells using time-dependent bio-heat equation and Nd: YAG lasers. Arch Cancer Res 4: 2 .

36. Alireza Heidari (2016) Quantitative structure-activity relationship (QSAR) approximation for cadmium oxide (CdO) and Rhodium (III) Oxide (Rh2O3) nanoparticles as anti-cancer drugs for the catalytic formation of proviral DNA from viral RNA using multiple linear and non-linear correlation approach. Ann Clin Lab Res 4: 1.

37. Alireza Heidari (2016) Biomedical study of cancer cells DNA therapy using laser irradiations at presence of intelligent nanoparticles. J Biomedical Sci 5: 2.

38. Alireza Heidari (2016) Measurement the amount of vitamin D2 (Ergocalciferol), vitamin D3 (Cholecalciferol) and absorbable Calcium (Ca2+), Iron (II) $(\mathrm{Fe} 2+)$, Magnesium (Mg2+), Phosphate (PO4-) and Zinc (Zn2+) in apricot using high-performance liquid chromatography (HPLC) and spectroscopic techniques. J Biom Biostat 7: 292.

39. Alireza Heidari (2016) Spectroscopy and quantum mechanics of the helium dimer $(\mathrm{He} 2+)$, neon dimer $(\mathrm{Ne} 2+)$, argon dimer (Ar2+), krypton dimer ( $\mathrm{Kr} 2+)$, xenon dimer (Xe2+), radon dimer (Rn2+) and ununoctium dimer (Uuo2+) molecular cations. Chem Sci J 7: e112.

40. Alireza Heidari (2016) Human toxicity photodynamic therapy studies on DNA/RNA complexes as a promising new sensitizer for the treatment of malignant tumors using bio-spectroscopic techniques. J Drug Metab Toxicol 7: e129.

41. Alireza Heidari (2016) Novel and stable modifications of intelligent cadmium oxide ( $\mathrm{CdO}$ ) nanoparticles as anti-cancer drug in formation of nucleic acids complexes for human cancer cells' treatment. Biochem Pharmacol (Los Angel) 5: 207.

42. Alireza Heidari (2016) A combined computational and QM/ MM molecular dynamics study on boron nitride nanotubes (BNNTs), amorphous boron nitride nanotubes (a-BNNTs) and hexagonal boron nitride nanotubes (h-BNNTs) as hydrogen storage. Struct Chem Crystallogr Commun 2: 1.

43. Alireza Heidari (2016) Pharmaceutical and analytical chemistry study of cadmium oxide $(\mathrm{CdO})$ nanoparticles synthesis methods and properties as anti-cancer drug and its effect on human cancer cells. Pharm Anal Chem Open Access 2: 113.

44. Alireza Heidari (2016) A chemotherapeutic and biospectroscopic investigation of the interaction of double-standard DNA/RNA-binding molecules with cadmium oxide (CdO) and Rhodium (III) Oxide (Rh2O3) nanoparticles as anti-cancer drugs for cancer cells' treatment. Chemo Open Access 5: e129.

45. Alireza Heidari (2016) Pharmacokinetics and experimental therapeutic study of DNA and other biomolecules using lasers: Advantages and applications. J Pharmacokinet Exp Ther 1: e005.

46. Alireza Heidari (2016) Determination of ratio and stability constant of DNA/RNA in human cancer cells and cadmium oxide ( $\mathrm{CdO}$ ) nanoparticles complexes using analytical electrochemical and spectroscopic techniques. Insights Anal Electrochem 2: 1

47. Alireza Heidari (2016) Discriminate between antibacterial and non-antibacterial drugs artificial neutral networks of a multilayer perceptron (MLP) type using a set of topological descriptors. J Heavy Met Toxicity Dis 1: 2.
48. Alireza Heidari (2016) Combined theoretical and computational study of the belousov-zhabotinsky chaotic reaction and curtius rearrangement for synthesis of mechlorethamine, cisplatin, streptozotocin, cyclophosphamide, melphalan, busulphan and bcnu as anti-cancer drugs. Insights Med Phys 1: 2.

49. Alireza Heidari (2016) A translational biomedical approach to structural arrangement of amino acids' complexes: A combined theoretical and computational study. Transl Biomed 7: 2.

50. Alireza Heidari (2016) Ab initio and density functional theory (DFT) studies of dynamic NMR shielding tensors and vibrational frequencies of DNA/RNA and cadmium oxide (CdO) nanoparticles complexes in human cancer cells. J Nanomedine Biotherapeutic Discov 6: e144.

51. Alireza Heidari (2016) Molecular dynamics and monte-carlo simulations for replacement sugars in insulin resistance, obesity, LDL cholesterol, triglycerides, metabolic syndrome, Type 2 diabetes and cardiovascular disease: A glycobiological study. J Glycobiol 5: e111.

52. Alireza Heidari (2016) Synthesis and study of 5-[(Phenylsulfonyl)Amino]-1,3,4-Thiadiazole-2-Sulfonamide as potential anti-pertussis drug using chromatography and spectroscopy techniques. Transl Med (Sunnyvale) 6: e138.

53. Alireza Heidari (2016) Nitrogen, oxygen, phosphorus and sulphur heterocyclic anti-cancer nano drugs separation in the supercritical fluid of ozone (O3) using soave-redlichkwong (SRK) and pang-robinson (PR) equations. Electronic J Biol 12: 3.

54. Alireza Heidari (2016) An analytical and computational infrared spectroscopic review of vibrational modes in nucleic acids. Austin J Anal Pharm Chem 3: 1058.

55. Alireza Heidari, Christopher Brown (2016) Phase, composition and morphology study and analysis of Os-Pd/HfC nanocomposites. Nano Res Appl 2: 1.

56. Alireza Heidari, Christopher Brown (2016) Vibrational spectroscopic study of intensities and shifts of symmetric vibration modes of ozone diluted by cumene. International Journal of Advanced Chemistry 4: 5-9.

57. Alireza Heidari (2016) Study of the role of anti-cancer molecules with different sizes for decreasing corresponding bulk tumor multiple organs or tissues. Arch Can Res 4: 2.

58. Alireza Heidari (2016) Genomics and proteomics studies of zolpidem, necopidem, alpidem, saripidem, miroprofen, zolimidine, olprinone and abafungin as anti-tumor, peptide antibiotics, antiviral and central nervous system (CNS) drugs. J Data Mining Genomics \& Proteomics 7: e125.

59. Alireza Heidari (2016) Pharmacogenomics and pharmacoproteomics studies of phosphodiesterase-5 (PDE5) inhibitors and paclitaxel albumin-stabilized nanoparticles as sandwiched anti-cancer nano drugs between two DNA/ RNA molecules of human cancer cells. J Pharmacogenomics Pharmacoproteomics 7: e153.

60. Alireza Heidari (2016) Biotranslational medical and biospectroscopic studies of cadmium oxide $(\mathrm{CdO})$ nanoparticles-DNA/RNA straight and cycle chain complexes as potent anti-viral, anti-tumor and anti-microbial drugs: A clinical approach. Transl Biomed 7: 2.

61. Alireza Heidari (2016) A comparative study on simultaneous determination and separation of adsorbed cadmium oxide ( $\mathrm{CdO})$ nanoparticles on DNA/RNA of human cancer cells using biospectroscopic techniques and dielectrophoresis (DEP) Method. Arch Can Res 4: 2. 
62. Alireza Heidari (2016) Cheminformatics and system chemistry of cisplatin, carboplatin, nedaplatin, oxaliplatin, heptaplatin and lobaplatin as anti-cancer nano drugs: A combined computational and experimental study. J Inform Data Min 1: 3.

63. Alireza Heidari (2016) Linear and non-linear quantitative structure-anti-cancer-activity relationship (QSACAR) study of hydrous ruthenium (IV) Oxide (RuO2) nanoparticles as non-nucleoside reverse transcriptase inhibitors (NNRTIs) and anti-cancer nano drugs. J Integr Oncol 5: e110.

64. Alireza Heidari (2016) Synthesis, characterization and biospectroscopic studies of cadmium oxide ( $\mathrm{CdO}$ ) nanoparticles-nucleic acids complexes absence of soluble polymer as a protective agent using nucleic acids condensation and solution reduction method. J Nanosci Curr Res 1: e101.

65. Alireza Heidari (2016) Coplanarity and collinearity of 4'-dinonyl-2,2'-bithiazole in one domain of bleomycin and pingyangmycin to be responsible for binding of cadmium oxide (CdO) nanoparticles to DNA/RNA bidentate ligands as anti-tumor nano drug. Int J Drug Dev \& Res 8: 007-008.

66. Alireza Heidari (2016) A Pharmacovigilance study on linear and non-linear quantitative structure (chromatographic) retention relationships (QSRR) models for the prediction of retention time of anti-cancer nano drugs under synchrotron radiations. J Pharmacovigil 4: e161.

67. Alireza Heidari (2016) Nanotechnology in preparation of semipermeable polymers. J Adv Chem Eng 6: 157.

68. Alireza Heidari (2016) A gastrointestinal study on linear and non-linear quantitative structure (chromatographic) retention relationships (QSRR) models for analysis 5-aminosalicylates nano particles as digestive system nano drugs under synchrotron radiations. J Gastrointest Dig Syst 6: e119.

69. Alireza Heidari (2016) DNA/RNA fragmentation and cytolysis in human cancer cells treated with diphthamide nano particles derivatives. Biomedical Data Mining 5: e102.

70. Alireza Heidari (2016) A successful strategy for the prediction of solubility in the construction of quantitative structure-activity relationship (QSAR) and quantitative structure-property relationship (QSPR) under synchrotron radiations using genetic function approximation (GFA) algorithm. J Mol Biol Biotechnol 1: 1 .

71. Alireza Heidari (2016) Computational study on molecular structures of C20, C60, C240, C540, C960, C2160 and C3840 fullerene nano molecules under synchrotron radiations using fuzzy logic. J Material Sci Eng 5: 282.

72. Alireza Heidari (2016) Graph theoretical analysis of zigzag polyhexamethylene biguanide, polyhexamethylene adipamide, polyhexamethylene biguanide gauze and polyhexamethylene biguanide hydrochloride (PHMB) boron nitride nanotubes (BNNTs), amorphous boron nitride nanotubes (a-BNNTs) and hexagonal boron nitride nanotubes (h-BNNTs). J Appl Computat Math 5: e143.

73. Alireza Heidari (2016) The impact of high resolution imaging on diagnosis. Int J Clin Med Imaging 3: 1000e101.

74. Alireza Heidari (2016) A comparative study of conformational behavior of isotretinoin (13-Cis Retinoic Acid) and tretinoin (All-Trans Retinoic Acid (ATRA)) nano particles as anti-cancer nano drugs under synchrotron radiations using hartree-fock (HF) and density functional theory (DFT) methods. Insights in Biomed 1: 2.

75. Alireza Heidari (2016) Advances in logic, operations and computational mathematics. J Appl Computat Math 5: e144.

76. Alireza Heidari (2016) Mathematical equations in predicting physical behavior. J Appl Computat Math 5: e145.
77. Alireza Heidari (2016) Chemotherapy a last resort for cancer treatment. Chemo Open Access 5: e130.

78. Alireza Heidari (2016) Separation and pre-concentration of metal cations-DNA/RNA chelates using molecular beam mass spectrometry with tunable vacuum ultraviolet (VUV) synchrotron radiation and various analytical methods. Mass Spectrom Purif Tech 2: e101.

79. Alireza Heidari (2016) Yoctosecond quantitative structure-activity relationship (QSAR) and quantitative structure-property relationship (QSPR) under synchrotron radiations studies for prediction of solubility of anti-cancer nano drugs in aqueous solutions using genetic function approximation (GFA) algorithm. J Pharm Pharm Res 1: 6.

80. Alireza Heidari (2016) Cancer risk prediction and assessment in human cells under synchrotron radiations using quantitative structure activity relationship (QSAR) and quantitative structure properties relationship (QSPR) Studies. Int J Clin Med Imaging 3: 516.

81. Alireza Heidari (2016) A novel approach to biology. Electronic J Biol 12: 4.

82. Alireza Heidari (2016) Innovative biomedical equipment's for diagnosis and treatment. J Bioengineer \& Biomedical Sci 6: e123.

83. Alireza Heidari (2016) Integrating precision cancer medicine into healthcare, medicare reimbursement changes and the practice of oncology: Trends in oncology medicine and practices. J Oncol Med \& Pract 1: e101.

84. Alireza Heidari (2016) Promoting convergence in biomedical and biomaterials sciences and silk proteins for biomedical and biomaterials applications: An introduction to materials in medicine and bioengineering perspectives. $J$ Bioengineer \& Biomedical Sci 6: e126.

85. Alireza Heidari (2017) X-Ray fluorescence and X-Ray diffraction analysis on discrete element modeling of nano powder metallurgy processes in optimal container design. $J$ Powder Metall Min 6: e136.

86. Alireza Heidari (2017) Biomolecular spectroscopy and dynamics of nano-sized molecules and clusters as cross-linking-induced anti-cancer and immune-oncology nano drugs delivery in DNA/RNA of human cancer cells' membranes under synchrotron radiations: A payload-based perspective. Arch Chem Res 1: 2.

87. Alireza Heidari (2017) Deficiencies in repair of double-standard DNA/RNA-binding molecules identified in many types of solid and liquid tumors oncology in human body for advancing cancer immunotherapy using computer simulations and data analysis. J Appl Bioinforma Comput Biol 6: 1.

88. Alireza Heidari (2017) Electronic coupling among the five nanomolecules shuts down quantum tunneling in the presence and absence of an applied magnetic field for indication of the dimer or other provide different influences on the magnetic behavior of single molecular magnets (SMMs) as qubits for quantum computing. Glob J Res Rev 4: 2.

89. Alireza Heidari (2017) Polymorphism in Nano-Sized Graphene Ligand-Induced Transformation of Au38-xAgx/xCux(SPh-tBu)24 to Au36-xAgx/xCux(SPh-tBu)24 ( $x=1-12)$ Nanomolecules for Synthesis of Au144-xAgx/xCux[(SR)60, (SC4)60, (SC6)60, (SC12)60, (PET)60, (p-MBA)60, (F)60, (Cl)60, (Br)60, (I)60, (At)60, (Uus)60 and (SC6H13)60] Nano Clusters as Anti-Cancer Nano Drugs. J Nanomater Mol Nanotechnol 6: 3 .

90. Alireza Heidari (2017) Biomedical resource oncology and data mining to enable resource discovery in medical, medicinal, clinical, pharmaceutical, chemical and translational 
research and their applications in cancer research. Int $\mathrm{J}$ Biomed Data Min 6: e103.

91. Alireza Heidari (2017) Study of Synthesis, pharmacokinetics, pharmacodynamics, dosing, stability, safety and efficacy of olympiadane nanomolecules as agent for cancer enzymotherapy, immunotherapy, chemotherapy, radiotherapy, hormone therapy and targeted therapy under synchrotorn radiation. J Dev Drugs 6: E154.

92. Alireza Heidari (2017) A novel approach to future horizon of top seven biomedical research topics to watch in 2017: Alzheimer's, Ebola, Hypersomnia, Human Immunodeficiency Virus (HIV), Tuberculosis (TB), Microbiome/Antibiotic Resistance and Endovascular Stroke. J Bioengineer \& Biomedical Sci 7: e127.

93. Alireza Heidari (2017) Opinion on Computational Fluid Dynamics (CFD) technique. Fluid Mech Open Acc 4: 157.

94. Alireza Heidari (2017) Concurrent diagnosis of oncology influence outcomes in emergency general surgery for colorectal cancer and Multiple Sclerosis (MS) treatment using Magnetic Resonance Imaging (MRI) and Au329(SR)84, Au329xAgx(SR)84, Au144(SR)60, Au68(SR)36, Au30(SR)18, Au102(SPh)44, Au38(SPh)24, Au38(SC2H4Ph)24, Au21S(SAdm)15, Au36(pMBA)24 and Au25(pMBA)18 Nano Clusters. J Surgery Emerg Med 1: 21.

95. Alireza Heidari (2017) Developmental Cell Biology in adult stem cells death and autophagy to trigger a preventive allergic reaction to common airborne allergens under synchrotron radiation using nanotechnology for therapeutic goals in particular allergy shots (Immunotherapy). Cell Biol Henderson 6: 1.

96. Alireza Heidari (2017) Changing metal powder characteristics for elimination of the heavy metals toxicity and diseases in disruption of Extracellular Matrix (ECM) proteins adjustment in cancer metastases induced by osteosarcoma, chondrosarcoma, carcinoid, carcinoma, ewing's sarcoma, fibrosarcoma and secondary hematopoietic solid or soft tissue tumors. J Powder Metall Min 6: 170.

97. Alireza Heidari (2017) Nanomedicine-based combination anti-cancer therapy between nucleic acids and anti-cancer nano drugs in covalent nano drugs delivery systems for selective imaging and treatment of human brain tumors using hyaluronic acid, alguronic acid and sodium hyaluronate as anti-cancer nano drugs and nucleic acids delivery under synchrotron radiation. Am J Drug Deliv 5: 2.

98. Alireza Heidari (2017) Clinical trials of dendritic cell therapies for cancer exposing vulnerabilities in human cancer cells' metabolism and metabolomics: New discoveries, unique features inform new therapeutic opportunities, biotech's bumpy road to the market and elucidating the biochemical programs that support cancer initiation and progression. J Biol Med Science 1: e103.

99. Alireza Heidari (2017) The design graphene-based nanosheets as a new nanomaterial in anti-cancer therapy and delivery of chemotherapeutics and biological nano drugs for liposomal anti-cancer nano drugs and gene delivery. Br Biomed Bull 5: 305.

100. Alireza Heidari (2017) Integrative approach to biological networks for emerging roles of proteomics, genomics and transcriptomics in the discovery and validation of human colorectal cancer biomarkers from DNA/RNA sequencing data under synchrotron radiation. Transcriptomics 5: E117.

101. Alireza Heidari (2017) Elimination of the heavy metals toxicity and diseases in disruption of Extracellular Matrix (ECM) proteins and cell adhesion intelligent nanomole- cules adjustment in cancer metastases using metalloenzymes and under synchrotron radiation. Lett Health Biol Sci 2: 1-4.

102. Alireza Heidari (2017) Treatment of breast cancer brain metastases through a targeted nanomolecule drug delivery system based on dopamine functionalized MultiWall Carbon Nanotubes (MWCNTs) coated with nano Graphene Oxide (GO) and Protonated Polyaniline (PANI) in situ during the polymerization of aniline autogenic nanoparticles for the delivery of anti-cancer nano drugs under synchrotron radiation. Br J Res 4: 16.

103. Alireza Heidari (2017) Sedative, analgesic and ultrasound-mediated gastrointestinal nano drugs delivery for gastrointestinal endoscopic procedure, nano drug-induced gastrointestinal disorders and nano drug treatment of gastric acidity. Res Rep Gastroenterol 1: 1.

104. Alireza Heidari (2017) Synthesis, pharmacokinetics, pharmacodynamics, dosing, stability, safety and efficacy of orphan nano drugs to treat high cholesterol and related conditions and to prevent cardiovascular disease under synchrotron radiation. J Pharm Sci Emerg Drugs 5: 1.

105. Alireza Heidari (2017) Non-Linear compact proton synchrotrons to improve human cancer cells and tissues treatments and diagnostics through particle therapy accelerators with monochromatic microbeams. J Cell Biol Mol Sci 2: 1-5.

106. Alireza Heidari (2017) Design of targeted metal chelation therapeutics nanocapsules as colloidal carriers and Blood-Brain Barrier (BBB) translocation to targeted deliver anti-cancer nano drugs into the human brain to treat alzheimer's disease under synchrotron radiation. J Nanotechnol Material Sci 4: 1-5.

107. Ricardo Gobato, Alireza Heidari (2017) Calculations using quantum chemistry for inorganic molecule simulation BeLi2SeSi. Science Journal of Analytical Chemistry 5: 76-85.

108. Alireza Heidari (2017) Different high-resolution simulations of medical, medicinal, clinical, pharmaceutical and therapeutics oncology of human lung cancer translational anti-cancer nano drugs delivery treatment process under synchrotron and $\mathrm{x}$-ray radiations. J Med Oncol 1: 1.

109. Alireza Heidari (2017) A modern ethnomedicinal technique for transformation, prevention and treatment of human malignant gliomas tumors into human benign gliomas tumors under synchrotron radiation. Am J Ethnomed 1: 10.

110. Alireza Heidari (2017) Active targeted nanoparticles for anti-cancer nano drugs delivery across the blood-brain barrier for human brain cancer treatment, Multiple Sclerosis (MS) and Alzheimer's diseases using chemical modifications of anti-cancer nano drugs or drug-nanoparticles through Zika Virus (ZIKV) nanocarriers under synchrotron radiation. J Med Chem Toxicol 2: 1-5.

111. Alireza Heidari (2017) Investigation of medical, medicinal, clinical and pharmaceutical applications of Estradiol, Mestranol (Norlutin), Norethindrone (NET), Norethisterone Acetate (NETA), Norethisterone Enanthate (NETE) and testosterone nanoparticles as biological imaging, cell labeling, anti-microbial agents and anti-cancer nano drugs in nanomedicines based drug delivery systems for anti-cancer targeting and treatment. Parana Journal of Science and Education (PJSE) 4: 10-19.

112. Alireza Heidari (2017) A comparative computational and experimental study on different vibrational biospectroscopy methods, techniques and applications for human cancer cells in tumor tissues simulation, modeling, research, 
diagnosis and treatment. Open J Anal Bioanal Chem 1: 14-20.

113. Alireza Heidari (2017) Combination of DNA/RNA Ligands and Linear/Non-Linear Visible-Synchrotron Radiation-Driven N-Doped Ordered Mesoporous Cadmium Oxide (CdO) Nanoparticles Photocatalysts Channels Resulted in an Interesting Synergistic Effect Enhancing Catalytic Anti-Cancer Activity. Enz Eng 6: 1.

114. Alireza Heidari (2017) Modern Approaches in Designing Ferritin, Ferritin Light Chain, Transferrin, Beta-2 Transferrin and Bacterioferritin-Based Anti-Cancer Nano Drugs Encapsulating Nanosphere as DNA-Binding Proteins from Starved Cells (DPS). Mod Appro Drug Des 1: 1.

115. Alireza Heidari (2017) Potency of Human Interferon $\beta-1 a$ and Human Interferon $\beta-1 \mathrm{~b}$ in Enzymotherapy, Immunotherapy, Chemotherapy, Radiotherapy, Hormone Therapy and Targeted Therapy of Encephalomyelitis Disseminate/ Multiple Sclerosis (MS) and Hepatitis A, B, C, D, E, F and $G$ Virus Enter and Targets Liver Cells. J Proteomics Enzymol 6: 1.

116. Alireza Heidari (2017) Transport therapeutic active targeting of human brain tumors enable anti-cancer nanodrugs delivery across the Blood-Brain Barrier (BBB) to treat brain diseases using nanoparticles and nanocarriers under synchrotron radiation. J Pharm Pharmaceutics 4: 1-5.

117. Alireza Heidari, Christopher Brown (2017) Combinatorial therapeutic approaches to DNA/RNA and Benzylpenicillin (Penicillin G), Fluoxetine Hydrochloride (Prozac and Sarafem), Propofol (Diprivan), Acetylsalicylic Acid (ASA) (Aspirin), Naproxen Sodium (Aleve and Naprosyn) and Dextromethamphetamine nanocapsules with surface conjugated DNA/RNA to targeted nano drugs for enhanced anti-cancer efficacy and targeted cancer therapy using nano drugs delivery systems. Ann Adv Che 1: 61-69.

118. Alireza Heidari (2017) High-resolution simulations of human brain cancer translational nano drugs delivery treatment process under synchrotron radiation. J Transl Res 1: 1-3.

119. Alireza Heidari (2017) Investigation of Anti-Cancer Nano Drugs' Effects' Trend on Human Pancreas Cancer Cells and Tissues Prevention, Diagnosis and Treatment Process under Synchrotron and X-Ray Radiations with the Passage of Time Using Mathematica. Current Trends Anal Bioanal Chem 1: 36-41.

120. Alireza Heidari (2017) Pros and Cons Controversy on Molecular Imaging and Dynamics of Double-Standard DNA RNA of Human Preserving Stem Cells-Binding Nano Molecules with Androgens/Anabolic Steroids (AAS) or Testosterone Derivatives through Tracking of Helium-4 Nucleus (Alpha Particle) Using Synchrotron Radiation. Arch Biotechnol Biomed 1: 67-100.

121. Alireza Heidari (2017) Visualizing metabolic changes in probing human cancer cells and tissues metabolism using Vivo $1 \mathrm{H}$ or Proton NMR, ${ }^{13} \mathrm{C}$ NMR, ${ }^{15} \mathrm{~N}$ NMR and ${ }^{31} \mathrm{P}$ NMR spectroscopy and self-organizing maps under synchrotron radiation. SOJ Mater Sci Eng 5: 1-6.

122. Alireza Heidari (2017) Cavity Ring-Down Spectroscopy (CRDS), Circular Dichroism Spectroscopy, Cold Vapour Atomic Fluorescence Spectroscopy and Correlation Spectroscopy comparative study on malignant and benign human cancer cells and tissues with the passage of time under synchrotron radiation. Enliven: Challenges Cancer Detect Ther 4: E001.

123. Alireza Heidari (2017) Laser Spectroscopy, Laser-Induced Breakdown Spectroscopy and Laser-Induced Plas- ma Spectroscopy comparative study on malignant and benign human cancer cells and tissues with the passage of time under synchrotron radiation. Int J Hepatol Gastroenterol 3: 79-84

124. Alireza Heidari (2017) Time-Resolved Spectroscopy and Time-Stretch Spectroscopy comparative study on malignant and benign human cancer cells and tissues with the passage of time under synchrotron radiation. Enliven: Pharmacovigilance and Drug Safety 4: e001.

125. Alireza Heidari (2017) Overview of the Role of Vitamins in Reducing Negative Effect of Decapeptyl (Triptorelin Acetate or Pamoate Salts) on Prostate Cancer Cells and Tissues in Prostate Cancer Treatment Process through Transformation of Malignant Prostate Tumors into Benign Prostate Tumors under Synchrotron Radiation. Open $\mathrm{J}$ Anal Bioanal Chem 1: 21-26.

126. Alireza Heidari (2017) Electron Phenomenological Spectroscopy, Electron Paramagnetic Resonance (EPR) Spectroscopy and Electron Spin Resonance (ESR) Spectroscopy comparative study on malignant and benign human cancer cells and tissues with the passage of time under synchrotron radiation. Austin J Anal Pharm Chem 4: 1091.

127. Alireza Heidari (2017) Therapeutic nanomedicine different high-resolution experimental images and computational simulations for human brain cancer cells and tissues using nanocarriers deliver DNA/RNA to brain tumors under synchrotron radiation with the passage of time using Mathematica and MATLAB. Madridge J Nano Tech Sci 2: 77-83.

128. Alireza Heidari (2017) A consensus and prospective study on restoring Cadmium Oxide ( $\mathrm{CdO})$ nanoparticles sensitivity in recurrent ovarian cancer by extending the Cadmium Oxide $(\mathrm{CdO})$ nanoparticles-free interval using synchrotron radiation therapy as antibody-drug conjugate for the treatment of limited-stage small cell diverse epithelial cancers. Cancer Clin Res Rep 1: e001.

129. Alireza Heidari (2017) A novel and modern experimental imaging and spectroscopy comparative study on malignant and benign human cancer cells and tissues with the passage of time under white synchrotron radiation. Cancer Sci Res Open Access 4: 1-8.

130. Alireza Heidari (2017) Different high-resolution simulations of medical, medicinal, clinical, pharmaceutical and therapeutics oncology of human breast cancer translational nano drugs delivery treatment process under synchrotron and X-Ray radiations. J Oral Cancer Res 1: 12-17.

131. Alireza Heidari (2017) Vibrational Decihertz (dHz), Centihertz $(\mathrm{cHz})$, Millihertz $(\mathrm{mHz})$, Microhertz $(\mu \mathrm{Hz})$, Nanohertz $(\mathrm{nHz})$, Picohertz $(\mathrm{pHz})$, Femtohertz $(\mathrm{fHz})$, Attohertz $(\mathrm{aHz})$, Zeptohertz $(\mathrm{zHz})$ and Yoctohertz $(\mathrm{yHz})$ imaging and spectroscopy comparative study on malignant and benign human cancer cells and tissues under synchrotron radiation. International Journal of Biomedicine 7: 335-340.

132. Alireza Heidari (2017) Force Spectroscopy and Fluorescence Spectroscopy comparative study on malignant and benign human cancer cells and tissues with the passage of time under synchrotron radiation. EC Cancer 2: 239-246.

133. Alireza Heidari (2017) Photoacoustic Spectroscopy, Photoemission Spectroscopy and Photothermal Spectroscopy comparative study on malignant and benign human cancer cells and tissues with the passage of time under synchrotron radiation. BAOJ Cancer Res Ther 3: 45-52.

134. Alireza Heidari (2017) J-Spectroscopy, Exchange Spectroscopy (EXSY), Nuclear Overhauser Effect Spectroscopy (NOESY) and Total Correlation Spectroscopy 
(TOCSY) comparative study on malignant and benign human cancer cells and tissues under synchrotron radiation. EMS Eng Sci J 1: 6-13.

135. Alireza Heidari (2017) Neutron Spin Echo Spectroscopy and Spin Noise Spectroscopy comparative study on malignant and benign human cancer cells and tissues with the passage of time under synchrotron radiation. Int J Biopharm Sci 1: 103.

136. Alireza Heidari (2017) Vibrational Decahertz (daHz), Hectohertz $(\mathrm{hHz})$, Kilohertz $(\mathrm{kHz})$, Megahertz $(\mathrm{MHz})$, Gigahertz $(\mathrm{GHz})$, Terahertz $(\mathrm{THz})$, Petahertz $(\mathrm{PHz})$, Exahertz $(\mathrm{EHz})$, Zettahertz $(\mathrm{ZHz})$ and Yottahertz $(\mathrm{YHz})$ Imaging and Spectroscopy comparative study on malignant and benign human cancer cells and tissues under synchrotron radiation. Madridge J Anal Sci Instrum 2: 41-46.

137. Alireza Heidari (2018) Two-Dimensional Infrared Correlation Spectroscopy, Linear Two-Dimensional Infrared Spectroscopy and Non-Linear Two-Dimensional Infrared Spectroscopy comparative study on malignant and benign human cancer cells and tissues under synchrotron radiation with the passage of time. J Mater Sci Nanotechnol 6: 101.

138. Alireza Heidari (2018) Fourier Transform Infrared (FTIR) Spectroscopy, Near-Infrared Spectroscopy (NIRS) and Mid-Infrared Spectroscopy (MIRS) Comparative study on malignant and benign human cancer cells and tissues under synchrotron radiation with the passage of time. Int $J$ Nanotechnol Nanomed 3: 1-6.

139. Alireza Heidari (2018) Infrared Photo Dissociation Spectroscopy and Infrared Correlation Table Spectroscopy comparative study on malignant and benign human cancer cells and tissues under synchrotron radiation with the passage of time. Austin Pharmacol Pharm 3: 1011.

140. Alireza Heidari (2017) Novel and transcendental prevention, diagnosis and treatment strategies for investigation of interaction among human blood cancer cells, tissues, tumors and metastases with synchrotron radiation under anti-cancer nano drugs delivery efficacy using MATLAB modeling and simulation. Madridge J Nov Drug Res 1: 18-24.

141. Alireza Heidari (2018) Comparative study on malignant and benign human cancer cells and tissues with the passage of time under synchrotron radiation. Open Access $\mathrm{J}$ Trans Med Res 2: 00026.

142. Marcia Regina Risso Gobato, Ricardo Gobato, Alireza Heidari (2018) Planting of Jaboticaba trees for landscape repair of degraded area. Landscape Architecture and Regional Planning 3: 1-9.

143. Alireza Heidari (2018) Fluorescence Spectroscopy, Phosphorescence Spectroscopy and Luminescence Spectroscopy comparative study on malignant and benign human cancer cells and tissues under synchrotron radiation with the passage of time. SMJ Clin Med Imaging 4: 1018.

144. Alireza Heidari (2018) Nuclear Inelastic Scattering Spectroscopy (NISS) and Nuclear Inelastic Absorption Spectroscopy (NIAS) Comparative study on malignant and benign human cancer cells and tissues under synchrotron radiation. Int J Pharm Sci 2: 1-14.

145. Alireza Heidari (2018) X-Ray Diffraction (XRD), Powder $X$-Ray Diffraction (PXRD) and Energy-Dispersive X-Ray Diffraction (EDXRD) Comparative study on malignant and benign human cancer cells and tissues under synchrotron radiation. J Oncol Res 2: 1-14.

146. Alireza Heidari (2018) Correlation Two-Dimensional Nuclear Magnetic Resonance (NMR) (2D-NMR) (COSY) Imaging and spectroscopy comparative study on malignant and benign human cancer cells and tissues under synchrotron radiation. EMS Can Sci 1: 1.

147. Alireza Heidari (2018) Thermal Spectroscopy, Photothermal Spectroscopy, Thermal Microspectroscopy, Photothermal Microspectroscopy, Thermal Macrospectroscopy and Photothermal Macrospectroscopy Comparative study on malignant and benign human cancer cells and tissues with the passage of time under synchrotron radiation. SM J Biometrics Biostat 3: 1024.

148. Alireza Heidari (2018) A modern and comprehensive experimental biospectroscopic comparative study on human common cancers' cells, tissues and tumors before and after synchrotron radiation therapy. Open Acc J Oncol Med 1.

149. Alireza Heidari (2018) Heteronuclear correlation experiments such as Heteronuclear Single-Quantum Correlation Spectroscopy (HSQC), Heteronuclear Multiple-Quantum Correlation Spectroscopy (HMQC) and Heteronuclear Multiple-Bond Correlation Spectroscopy (HMBC) comparative study on malignant and benign human endocrinology and thyroid cancer cells and tissues under synchrotron radiation. J Endocrinol Thyroid Res 3: 555604.

150. Alireza Heidari (2018) Nuclear Resonance Vibrational Spectroscopy (NRVS), Nuclear Inelastic Scattering Spectroscopy (NISS), Nuclear Inelastic Absorption Spectroscopy (NIAS) and Nuclear Resonant Inelastic X-Ray Scattering Spectroscopy (NRIXSS) comparative study on malignant and benign human cancer cells and tissues under synchrotron radiation. Int J Bioorg Chem Mol Biol 6: 1-5.

151. Alireza Heidari (2018) A novel and modern experimental approach to vibrational circular dichroism spectroscopy and video spectroscopy comparative study on malignant and benign human cancer cells and tissues with the passage of time under white and monochromatic synchrotron radiation. Glob J Endocrinol Metab 1.

152. Heidari A (2018) Pros and Cons Controversy on Heteronuclear Correlation Experiments such as Heteronuclear Single-Quantum Correlation Spectroscopy (HSQC), Heteronuclear Multiple-Quantum Correlation Spectroscopy (HMQC) and Heteronuclear Multiple-Bond Correlation Spectroscopy (HMBC) comparative study on malignant and benign human cancer cells and tissues under synchrotron radiation. EMS Pharma J 1: 002-008.

153. Heidari A (2018) Saturated spectroscopy and unsaturated spectroscopy comparative study on malignant and benign human cancer cells and tissues with the passage of time under synchrotron radiation. Imaging J Clin Medical Sci 5: 001-007.

154. Namdari M, Eatemadi A, Soleimaninejad M, Hammed AT (2017) A brief review on the application of nanoparticle enclosed herbal medicine for the treatment of infective endocarditis. Biomedicine \& Pharmacotherapy 87: 321-331.

155. Kiew TY, Cheow WS, Hadinoto K (2015) Preserving the supersaturation generation capability of amorphous drug-polysaccharide nanoparticle complex after freeze drying. International Journal of Pharmaceutics 484: 115-123.

156. Moghimi SM, Wibroe PP, Helvig SY, Farhangrazi ZS, Hunter AC (2012) Genomic perspectives in inter-individual adverse responses following nanomedicine administration: The way forward. Advanced Drug Delivery Reviews 64: 1385-1393.

157. Gil PR, Hühn D, del Mercato LL, Sasse D, Parak WJ (2010) Nanopharmacy: Inorganic nanoscale devices as vectors and active compounds. Pharmacological Research 62: 115-125. 
158. Rzigalinski BA, Strobl JS (2009) Cadmium-containing nanoparticles: Perspectives on pharmacology and toxicology of quantum dots. Toxicology and Applied Pharmacology 238: $280-288$.

159. Fako VE, Furgeson DY (2009) Zebrafish as a correlative and predictive model for assessing biomaterial nanotoxicity. Advanced Drug Delivery Reviews 61: 478-486.

160. Sainz V, Conniot J, Matos AI, Peres C, Zupanǒiǒ E, et al. (2015) Regulatory aspects on nanomedicines. Biochemical and Biophysical Research Communications 468: 504-510.

161. Duncan R, Vicent MJ (2010) Do HPMA copolymer conjugates have a future as clinically useful nanomedicines? A critical overview of current status and future opportunities. Advanced Drug Delivery Reviews 62: 272-282.

162. Zhou X, Che L, Wei Y, Dou Y, Chen S, et al. (2014) Facile route to versatile nanoplatforms for drug delivery by onepot self-assembly. Acta Biomaterialia 10: 2630-2642.

163. Wibroe PP, Ahmadvand D, Oghabian MA, Yaghmur A Moghimi SM (2016) An integrated assessment of morphology, size, and complement activation of the PEGylated liposomal doxorubicin products Doxil $\circledast$, Caelyx $®$, DOXOrubicin, and SinaDoxosome. Journal of Controlled Release 221: 1-8.

164. Nguyen MH, Yu H, Dong B, Hadinoto K (2016) A supersaturating delivery system of silibinin exhibiting high payload achieved by amorphous nano-complexation with chitosan. European Journal of Pharmaceutical Sciences 89: 163-171.

165. (2014) Special Issue Title Page. Biotechnology Advances 32: iii.
166. Beija M, Salvayre R, Viguerie NL, Marty JD (2012) Colloidal systems for drug delivery: From design to therapy. Trends in Biotechnology 30: 485-496.

167. Vaishali A, Varma KM, Bhupathi PA, Bharath TS, Ramesh MV, et al. (2017) In vitro evaluation of antimicrobial efficacy of $2 \%$ chlorhexidine loaded electrospun nanofibers. Journal of Pierre Fauchard Academy (India Section) 31: 105-108.

168. Bawa R (2009) NanoBiotech 2008: Exploring global advances in nanomedicine. Nanomedicine: Nanotechnology, Biology and Medicine 5: 5-7.

169. Marianecci C, Petralito S, Rinaldi F, Hanieh PN, Carafa M (2016) Some recent advances on liposomal and niosomal vesicular carriers. Journal of Drug Delivery Science and Technology 32: 256-269.

170. Patil S, Chaudhari K, Kamble R (2018) Electrospray technique for cocrystallization of phytomolecule. Journal of King Saud University - Science 30: 138-141.

171. Fonseca NA, Gregório AC, Valério-Fernandes A, Simões S, Moreira JN (2014) Bridging cancer biology and the patients' needs with nanotechnology-based approaches. Cancer Treatment Reviews 40: 626-635.

172. Bedi D, Musacchio T, Fagbohun OA, Gillespie JW, Deinnocentes P, et al. (2011) Delivery of siRNA into breast cancer cells via phage fusion protein-targeted liposomes. Nanomedicine: Nanotechnology, Biology and Medicine 7: 315-323.

173. Canal F, Sanchis J, Vicent MJ (2011) Polymer-drug conjugates as nano-sized medicines. Current Opinion in Biotechnology 22: 894-900. 